\title{
ANÁLISE TAFONÔMICA DOS FÓSSEIS DA MEGAFAUNA QUATERNÁRIA DO LAJEDÃO DO PATRÍCIO, JOÃO DOURADO (BAHIA), BRASIL
}

\author{
TAPHONOMIC ANALISYS OF FOSSIL QUATERNARY MEGAFAUNA OF THE LAJEDÃO DO \\ PATRÍCIO, JOÃO DOURADO (BAHIA), BRAZIL
}

\section{Fábio Henrique Cortes FARIA \& Ismar de Souza CARVALHO}

Centro de Ciências Matemáticas e da Natureza, Departamento de Geologia, Universidade Federal do Rio de Janeiro - UFRJ, Cidade Universitária, Av. Athos da Silveira Ramos, 274, Rio de Janeiro, Brasil. E-mails: fabiocortes22@gmail.com; ismar@geologia.ufrj.br

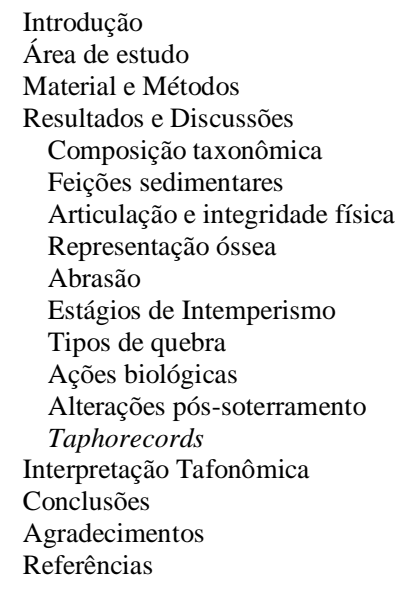

RESUMO - Realizou-se neste estudo a descrição e interpretação das modificações ósseas macroscópicas dos fósseis da megafauna do Quaternário, coletados no município de João Dourado, localidade do Lajedão do Patrício, estado da Bahia. Utilizando o conceito de taphorecords, caracterizaram-se os restos esqueletais em categorias tafonômicas de acordo com seu estado de preservação, inserindoos em grupos com histórias tafonômicas distintas, que são ossos ressedimentados e retrabalhados. A concentração fossilífera apresenta domínio das espécies Eremotherium laurillardi (Pilosa Megatheridae) e Notiomastodon platensis, devido sua abundância em biocenoses do Pleistoceno final - Holoceno inicial e da resistência de seus ossos. Os bioclastos apresentam orientação que indica a ação de fluxos na acumulação dos ossos. Bioclastos e clastos foram transportados e depositados em eventos de enchentes relâmpagos (flash floods), em drenagens temporárias, num contexto climático sazonal. A concentração fossilífera é parautóctone, monotípica e paucitáxica, predominando elementos com baixo e moderado potencial de transporte, respectivamente, indicando que os restos esqueletais que compõem a acumulação fossilífera foram transportados e retrabalhados de tanatocenoses próximas do local de acumulação e soterramento.

Palavras-chave: Bioclasto, Modificação óssea, Ressedimentação, Retrabalhamento.

\begin{abstract}
The description and interpretation of the macroscopic changes in the Quaternary megafauna bone fossils was performed in this study. The fossils were collected in the João Dourado County, Lajedão do Patrício locality, Bahia state. Using the taphorecords concept, skeletal remains were featured in taphonomic categories according to its state of preservation, inserting them into groups with different taphonomic histories, which are ressedimented and reworked bones. The fossiliferous concentration is dominated by Eremotherium laurillardi (Pilosa Megatheridae) and Notiomastodon platensis species, due to the abundance they have in the final Pleistocene - early Holocene biocenoses and the strength of your bones. The bioclasts present guidance indicating the action of the flows in the bones accumulation. Bioclasts and clasts were transported and deposited in lightning flooding events (flash floods) in temporary drainage and in a seasonal climate context. The fossiliferous concentration is parautoctone, monotypic and paucitaxic, predominating elements with low to moderate potential of the transportation, respectively, indicating that the skeletal remains that comprise fossiliferous accumulation were transported and reworked of the tanatocenoses near the accumulation and burial site.

Keywords: Bioclast, Bone modification, Ressedimentation, Reworking.
\end{abstract}

\section{INTRODUÇÃO}

A análise de assinaturas tafonômicas de ossos e carcaças fornece importantes informações para a compreensão dos processos envolvidos na acumulação e preservação de restos esqueletais, pois o processo de fossilização depende fortemente da relação existente entre os processos destrutivos (bióticos e abióticos) que afetam os ossos, como também da probabilidade de soterramento
(Behrensmeyer, 1978). Neste tipo de análise, os ossos são tratados como partículas sedimentares (bioclastos), pois o processo de alteração e acumulação está geralmente associado a processos sedimentares (Holz \& Simões, 2002). Portanto, auxiliando no esclarecimento de processos sedimentológicos responsáveis pela formação de associações fossilíferas. 
Concentrações fossilíferas com vertebrados quaternários são comuns no Nordeste brasileiro, sendo encontradas em cavernas (Cartelle, 1992; Auler et al., 2006), depósitos lacustres e tanques naturais (Porpino et al., 2004; Dantas et al., 2005; Ribeiro, 2014; Silva, 2008, Alves et al., 2007; Araújo-Júnior \& Porpino, 2011). A fauna destas concentrações fossilíferas é bem conhecida e diversificada (Cartelle, 1999; Bergqvist \& Almeida, 2004), com o domínio de mamíferos, porém carecendo de estudos tafonômicos mais acurados.

Análises tafonômicas de concentrações fossilíferas de vertebrados no Brasil são poucas, algumas de tafocenoses triássicas (Holz \& SoutoRibeiro, 2000; Bertoni-Machado et al., 2008), e apenas um estudo sobre concentrações do Cretáceo (Araújo-Júnior \& Marinho, 2013), e do Paleoceno (Bergqvist et al., 2011). Para depósitos do Pleistoceno muitas análises são baseadas em assinaturas muito superficiais (Alves et al., 2007; Araújo-Júnior \& Porpino, 2011; Araújo-Júnior et al., 2012), e poucas com métodos mais acurados (Silva, 2008; AraújoJúnior et al., 2013, 2015; Ribeiro, 2014).

Os fósseis analisados neste estudo são oriundos de sedimentos quaternários da zona rural do município de João Dourado, estado da Bahia. Esta análise representa o primeiro estudo tafonômico para a mastofauna do Quaternário da região.

O objetivo foi a classificação dos bioclastos em categorias de acordo com seu estágio de preservação, utilizando o conceito de taphorecord (Fernandez-López, 1987) para descrever os processos de acumulação e preservação. Deste modo, estudos tafonômicos de alterações ósseas da megafauna do Quaternário são ferramentas essenciais no esclarecimento dos processos responsáveis pela formação de associações fossilíferas.

\section{ÁREA DE ESTUDO}

O município de João Dourado, estado da Bahia, está situado a $452 \mathrm{~km}$ da capital, Salvador (Figura 1), inserido na microrregião de Irecê, centro-norte baiano. $\mathrm{O}$ depósito fossilífero situa-se na propriedade rural Fazenda Faveleira, no Lajedão

\section{do Patrício.}

As coordenadas de localização geográficas são $11^{0} 16$ '52,4' ' (latitude Sul), e 41 35'79' (longitude Oeste), DATUM WGS 84, com cota altimétrica de $820 \mathrm{~m}$

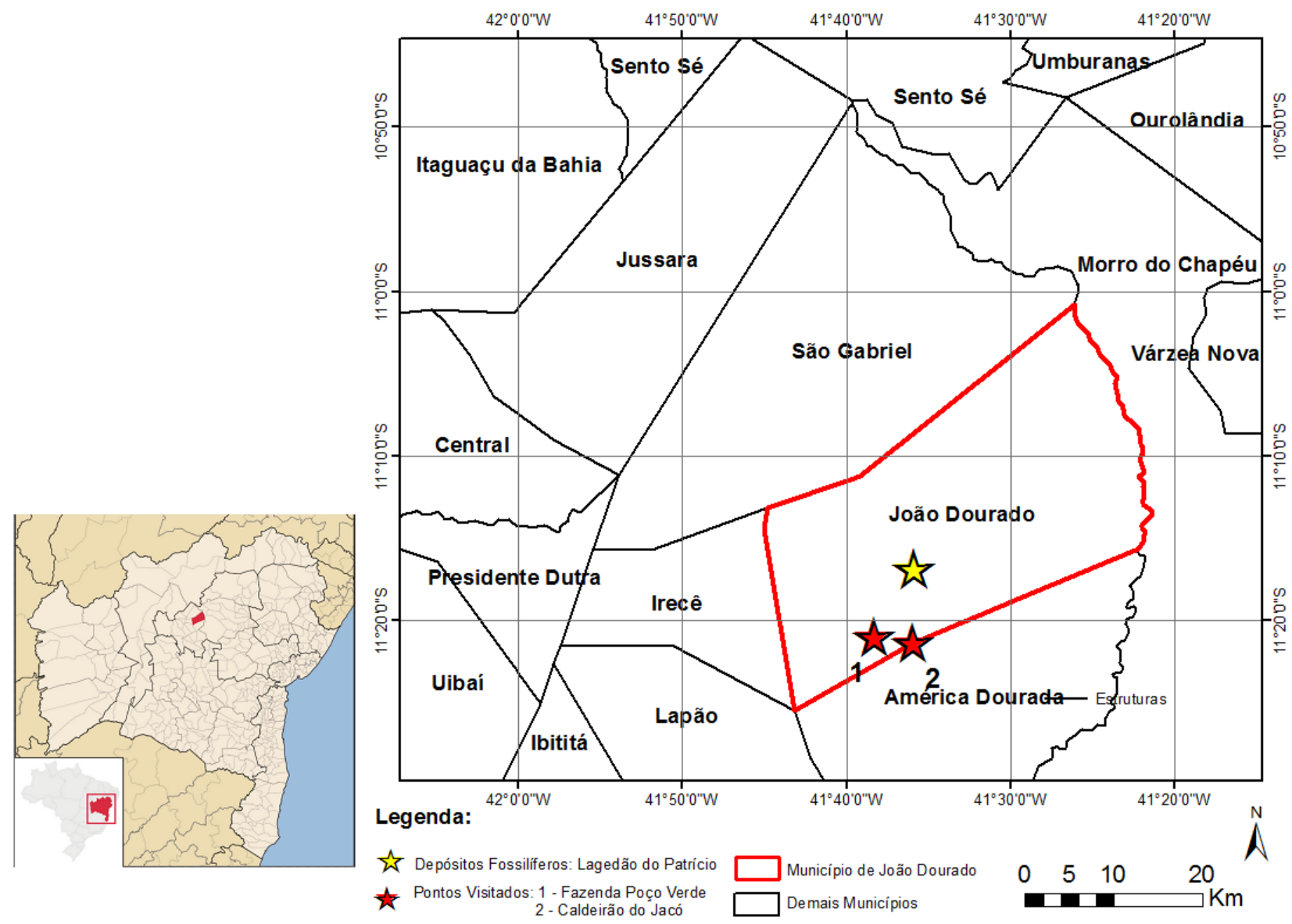

Figura 1 - A- mapa de localização do depósito fossilífero do Lajedão do Patrício. 
A área de estudo está localizada geomorfologicamente no Planalto Cárstico do Irecê, porção centro norte do estado da Bahia (Silva, 2005). Este apresenta altitudes que variam entre 650 e 800m (Laureano, 1998). Laureano (1998) e Pereira (1998) associaram tal feição geomorfológica ao ciclo de denudação ocorrido no terciário inferior, para as Bacias Sedimentares de Irecê e Una-Utinga. O relevo do município de João Dourado é levemente ondulado (Figura 2), onde é observado que o depósito fossilífero do Lajedão do Patrício, e pontos visitados que apresentaram a ocorrência de fósseis no passado, estão todos localizados em cabeceiras de drenagem temporárias ou próximo delas. Isto indica que o provável agente de acumulação e tendencialmente tafonômico estejam atrelados a processos fluviais.
A concentração fossilífera está localizada em uma depressão topográfica associada à geomorfologia cárstica da Bacia de Irecê (Figura 3). A determinação exata da feição geomorfológica onde são encontrados os fósseis é difícil de determinar, devido ao preenchimento sedimentar que impossibilita sua descrição e delimitação. Essa está associada a rochas carbonáticas neoproterozoicas da Formação Salitre (Grupo Ulna), sendo reconhecidas quatro unidades do topo para a base: Irecê, Jussara, Gabriel, Nova América (CPRM, 1985). O depósito fossilífero está encaixado em rochas da unidade Nova América, definida através de litotipos compostos por calcissiltitos, calcilutitos de cor creme e calcarenitos finos cinza e laminados (CPRM, 1985).

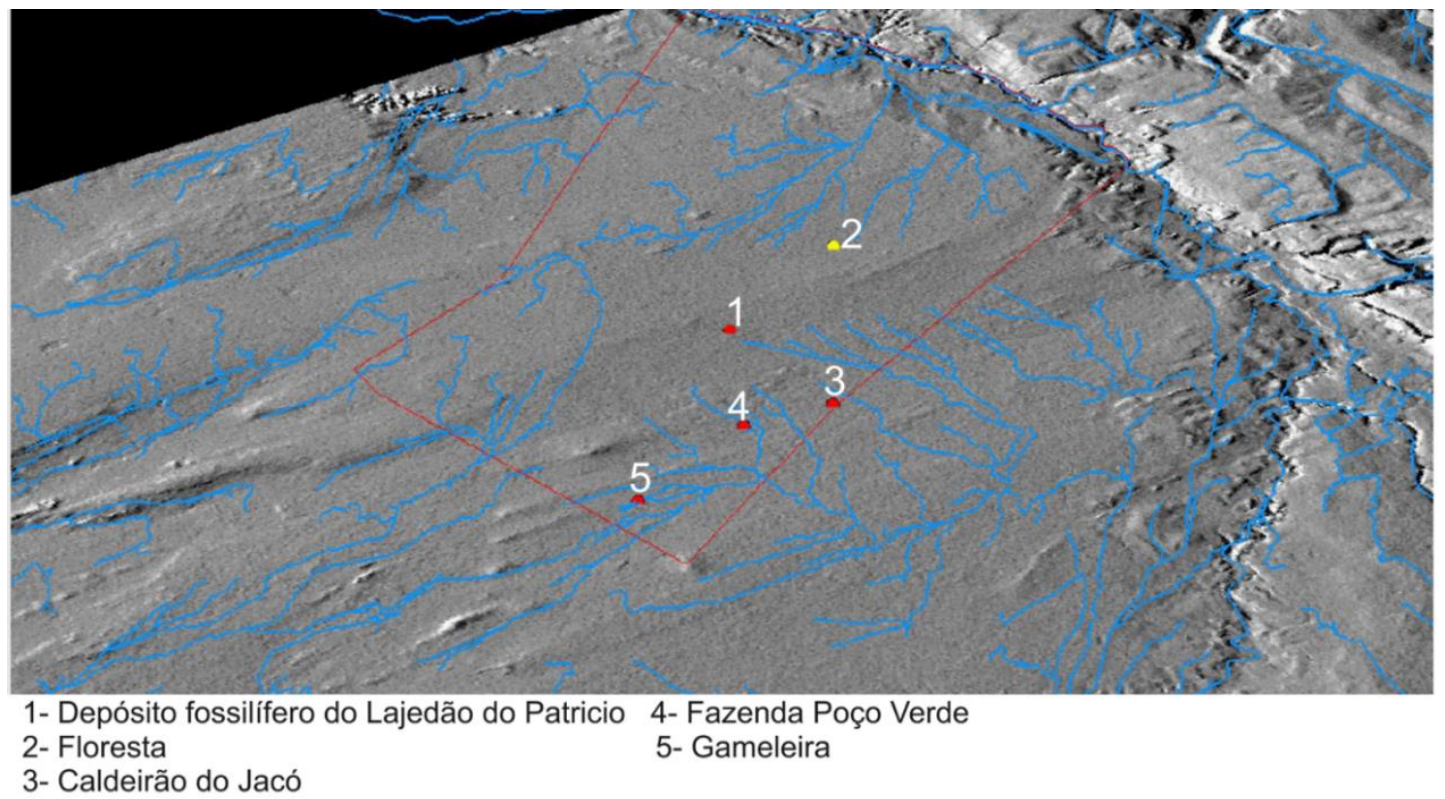

Figura 2 - Modelo 3D do relevo do município de João Dourado com localização dos sítios fossilíferos.

No perfil sedimentar do depósito foram identificadas cinco camadas (Figura 4). A primeira, da base para o topo, consiste em um conglomerado com clastos (subarredondados) e bioclastos apresentando direção de fluxo com campo de abrangência NW a WSW. Os bioclastos estão suportados por uma matriz síltica, apresentando espessura de $40 \mathrm{~cm}$. A segunda é um lutito bioturbado com invertebrados (gastrópodes pulmonados), com $30 \mathrm{~cm}$ de espessura de cor cinza. A terceira é um lutito bioturbado, com invertebrados similares ao do intervalo anterior, porém de menor tamanho. Já as camadas quatro e cinco consiste em uma mistura de areia e lama extremamente bioturbados, que são diferenciadas somente pela cor.

\section{MATERIAL E MÉTODOS}

A amostra é composta por 108 espécimes, estando 77 depositados na Coleção de Paleovertebrados do Departamento de Geologia da Universidade Federal do Rio de Janeiro (DEGEO/UFRJ), e 31 na Secretaria Municipal de Meio Ambiente de João Dourado. Correspondem a fragmentos de dentes, ossos cranianos e póscranianos, incluindo, crânio, costelas, membros e vértebras. Foram realizadas a quantificação dos elementos esqueletais, descrição das feições bioestratinômicas e sedimentares, e caracterização dos taphorecords. A identificação taxonômica foi realizada a partir de comparações com espécimes relativos depositados na Coleção de Paleovertebrados DEGEO/UFRJ, e com espécimes figurados na literatura especializada. 

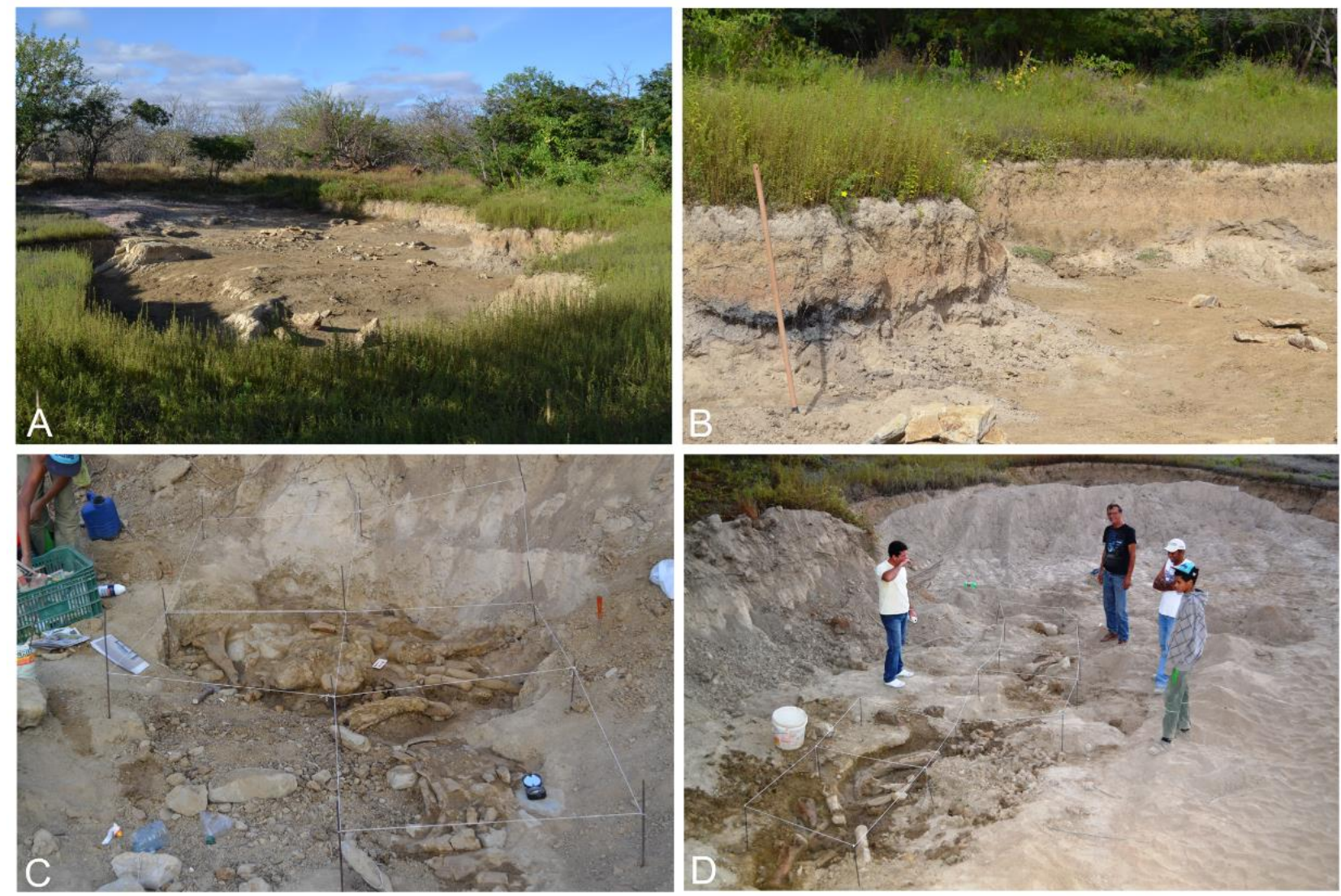

Figura 3 - A- visão geral do depósito fossilífero do Lajedão do Patrício; B- afloramento fossilífero; C e D- camada fossilífera; E- dolina estrutural; F- dolina de abatimento.

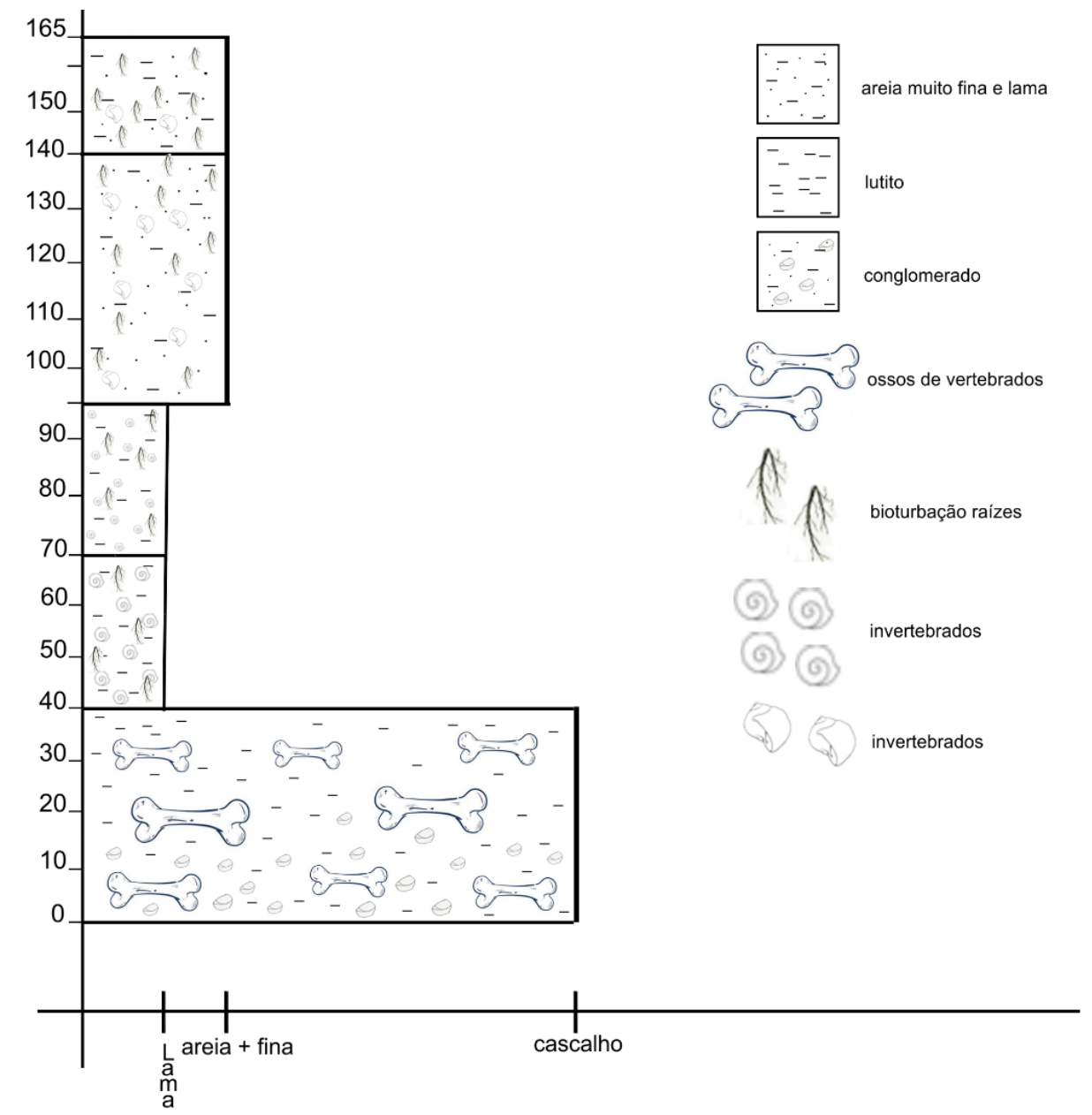

Figura 4 - Perfil sedimentar do depósito fossilífero do Lajedão do Patrício. 
$\mathrm{Na}$ quantificação dos elementos esqueletais foram utilizados os índices: Número de Partes Esqueletais Identificáveis (NISP) e Número Mínimo de Indivíduos (MNI) (Badgley, 1986). O índice NISP contabiliza fragmentos e elementos passíveis de identificação. O índice MNI foi estabelecido pela comparação dos ossos mais frequentes por táxon, pela proporção de tamanho e preservação.

As feições bioestratinômicas foram identificadas através de modificações, como: quebra (Shipman, 1981), representatividade esqueletal (Mazza et al., 2004), abrasão (Shipman, 1981), intemperismo (Behrensmeyer, 1978), integridade física (Behrensmeyer, 1991), ações biológicas e grau de articulação (Holz \& Simões, 2002).

Foram coletados dados referentes à orientação dos bioclastos e o grau de empacotamento da concentração fossilífera. A classificação desta última assinatura segue Holz \& Simões (2002). Para identificar o agente de acumulação dos restos esqueletais analisados foram conduzidas análises comparativas da proporção e frequência de ossos longos (proximal e distal), para identificar a influência de carnívoros/carniceiros no processo de acumulação (Richardson, 1980; Todd \& Rapson,1988). E também foi utilizado o Índice de Transportabilidade Fluvial (FTI) para restos esqueletais (Frison \& Todd, 1986), e "grau de equivalência hidráulica" (Behrensmeyer, 1975), para avaliar o grau de seleção por fluxos hidrodinâmicos. Também foram observadas feições de alterações pós-soterramento físicas (quebras, rachaduras e deformações) e químicas (corrosão, oxidação e revestimento).

Neste trabalho é aplicada pela primeira vez em depósitos de vertebrados brasileiros o termo Taphorecords (TR). Esta consiste em uma unidade paleontológica que compreende um fóssil ou grupo fóssil caracterizado por feições resultantes da modificação tafonômica (Fernandez-López, 1987). Na tafonomia, os termos ressedimentados e reelaborados não são sinônimos. O termo ressedimentado é utilizado para bioclastos que foram deslocados ao longo da superfície do solo antes do soterramento. Já o termo reelaborado (retrabalhamento tafonômico) refere-se à bioclastos que foram exumados e deslocados (Fernandez-Lopez 2011; Zunino et al., 2012).

Utilizou-se Lyman (1994) na adoção dos termos "espécime" e "elemento esqueletal". Espécime refere-se a uma unidade de observação, completo (elemento esqueletal) ou fragmento. Elemento esqueletal corresponde à unidade anatômica do esqueleto (ex; tíbia e úmero). Os termos "biocenose", "tanatocenose" e "tafocenose" também seguem as definições de Lyman (1994). O termo "megafauna" é utilizado para animais com mais de uma tonelada de massa corporal (Araújo-Júnior \& Porpino, 2011).

Para identificar a fidelidade espacial entre área fonte (tanatocenose) e local de soterramento e preservação, que são: acumulações preservadas in-situ, periféricas e concentrações ex-situ, foi utilizado Araújo-Júnior (2016). Concentrações in-situ são derivadas de restos esqueletais de indivíduos que morreram no interior do depósito. Periféricas são originadas por indivíduos que morreram próximo ao depósito, sendo transportados, acumulados e preservados no interior destes. Já associações fossilíferas $e x$-situ são originadas por restos de indivíduos que morreram muito distante do depósito, mas seus ossos foram acumulados e preservados em seu interior. Já, os termos "monotáxica", "paucitáxica" e "multitáxica" são utilizados segundo Eberth et al. (2007a, b): monotáxica, composto por uma espécie; paucitáxica, entre duas e nove espécies; multitáxica, concentrações com mais de nove espécies.

\section{RESULTADOS E DISCUSSÃO}

\section{Composição Taxonômica}

Das 108 amostras analisadas, 65 foram identificadas anatômica e taxonomicamente em nível de espécie. Alguns fragmentos foram identificados somente anatomicamente (18 amostras). Não foi possível assinalar em nível de gênero as 25 amostras restantes devido à fragmentação. A acumulação fossilífera do Lajedão do Patrício é composta por restos ósseos de megamamíferos, estando os valores de NISP e MNI listados na tabela 1. A tafocenose é pauxitáxica e monodominante (sensu Eberth et al., 2007b). Restos esqueletais da espécie Eremotherium laurillardi (Pilosa Megatheriidae) aparecem com maior frequência e Notiomastodon platensis é a segunda melhor representada.

No Lajedão do Patrício a preservação diferencial de ossos de elementos da megafauna, provavelmente está associada aos processos 
responsáveis pela acumulação dos bioclastos, que alteraram a fidelidade composicional da biocenose para a tafocenose. Em depósitos de tanque foram observadas características semelhantes (Araújo-Júnior et al. 2011, 2013), atribuindo tal fato a robustez e resistência dos ossos de megamamíferos. Brown et al. (2013) e Araújo-Júnior et al. (2011), em análises de preservação esqueletal relacionados à massa corporal, revelam tendencialmente devido à preservação diferencial de vertebrados de grande porte. Isto se deve à resistência dos ossos de grandes vertebrados a degradação, frente aos de pequenos vertebrados (Arribas \& Palmqvist, 1998).

Tabela 1 - Táxons identificados na acumulação fossilífera do Lajedão do Patrício, com valores de NISP e MNI.

\begin{tabular}{c|c|c|c}
\hline Grupo & Táxon & NISP & MNI \\
\hline \multirow{4}{*}{ Mamíferos } & Eremotherium laurillardi & 35 & 3 \\
\cline { 2 - 4 } & Notiomastodon platensis & 19 & 2 \\
\cline { 2 - 4 } & Toxodon platensis & 8 & 2 \\
\cline { 2 - 4 } & Glyptodon sp. & 3 & 2 \\
\hline
\end{tabular}

\section{Feições Sedimentares}

Durante a escavação e coleta foram observadas, na mesma concentração, padrões de deposição e acumulação distintos. Foram escavados e delimitados $10 \mathrm{~m}^{2}$ da camada fossilífera, sendo está dividida em dois setores com $5 \mathrm{~m}^{2}$. No primeiro setor (Figura $5 \mathrm{C} \mathrm{e} \mathrm{E}$ ), observa-se bioclastos frouxamente empacotados na matriz, com densidade espacial de 4 ossos $/ \mathrm{m}^{2}$. Já no segundo setor (Figura 5 D e F), observa-se bioclastos densamente empacotados, com densidade espacial de 5,2 ossos $/ \mathrm{m}^{2}$.

A orientação dos fósseis em planta reflete a influência de transporte hidráulico no processo de acumulação e deposição (Figura, 5A e B). Através das medidas de orientação dos bioclastos, observa-se que as direções predominantes são: WSW-ESE $(30,2 \%)$, WNWESE $(28 \%)$ e NW-SE $(18,6 \%)$. Isto indica que os restos esqueletais vieram de uma área fonte localizada entre NW e WSW do local de acumulação final.

No primeiro setor os bioclastos estão frouxamente empacotados, sugerindo que os bioclastos foram depositados e reelaborados por ação de fluxos de maior energia, devido a sua posição de repouso paralelo a linha de fluxo, seguida pela baixa deposição de siliciclásticos. Em correntes fortes, os ossos de membros (ex; tíbia, úmeros e rádios) depositam-se paralelos à direção de fluxo, com a extremidade mais densa posicionada a montante (Behrensmeyer, 1975).

O maior empacotamento observado no segundo setor é atribuído a uma sobrelevação do substrato, que causou a desaceleração do fluxo, gerando maior grau de empacotamento e posicionamento perpendicular ao fluxo, seguido por baixa deposição de siliciclásticos. Esta situação ocorre em águas rasas ou correntes fracas.

Isso ocorre porque os bioclastos não estão submersos na lâmina d'água (Behrensmeyer, 1975). Deste modo, a variação entre as direções dominantes indica oscilação de energia do fluxo, sendo observados ossos transportados e depositados em condições de maior e menor energia.

O material fossilífero analisado é encontrado em um conglomerado, com seixos e grânulos incorporados numa matriz lutítica. A grande proporção de bioclastos com tamanho entre $50 \mathrm{e}$ 150 mm (seção: articulação e integridade física) é equivalente hidraulicamente à fração cascalho (Behrensmeyer, 1975), o que indica a ação de fluxos de alta energia no transporte dos bioclastos analisados.

\section{Articulação E Integridade Física}

Todos os ossos da acumulação fossilífera do Lajedão do Patrício estão desarticulados, sugerindo longo período de exposição subaérea (Holz \& Simões, 2002). Em relação à integridade física, $62 \%$ são fragmentos ósseos $(<50 \%$ do osso), e espécimes completos ( $>95 \%$ preservado) e parciais (entre 50 e $95 \%$ do osso) correspondem a $19,4 \%$ e $18,6 \%$ dos bioclastos, respectivamente.

Segundo as classes tafonômicas de Holz et al. (2000), o depósito fossilífero apresenta as classes 3 e 4. A categoria 3 compreende elementos completos e desarticulados, representando exposição suficiente para desarticulação. Bioclastos da classe 4 compreendem ossos fragmentados e reelaborados. Estas classes tafonômicas são geradas por processos sedimentares distintos, resultando de processos sedimentares diacrônicos. A fragmentação pode ser originada por fatores físicos (transporte, retrabalhamento e compressão) (Holz \& Simões, 2002) e biológicos (trampling, carnívoros/carniceiros, raízes) (Behrensmeyer et al., 1995), sendo os processos de transporte e retrabalhamento os principais responsáveis pela fragmentação dos bioclastos analisados. 


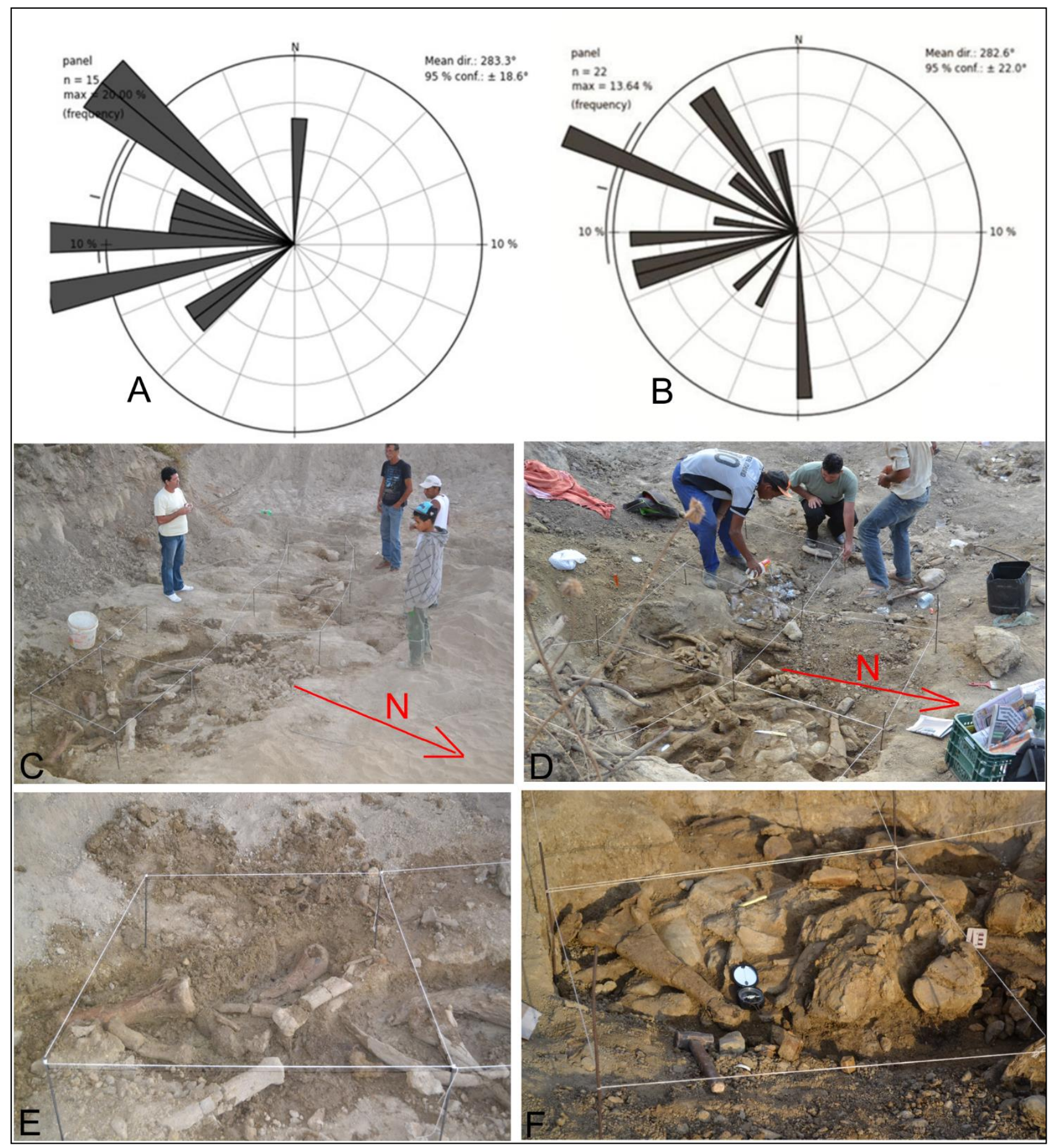

Figura 4 - A e B- diagrama de rosetas do setor A e B; C e D- acumulações fossilíferas dos setores A e B; E e F- visão aproximada dos setores $\mathrm{A}$ e $\mathrm{B}$, respectivamente. Grids de $1 \mathrm{~m}^{2}$.

\section{Representação Óssea}

Os ossos mais frequentes na acumulação fossilífera do Lajedão do Patrício são: costelas $(25,7 \%)$, dentes $(18,6 \%)$ e vértebras $(17,1 \%)$. Ulna $(4 \%)$, clavícula $(5,7 \%)$ e fêmur $(1,4 \%)$ estão pobremente representados. Costelas, dentes e vértebras são os elementos mais abundantes no esqueleto de vertebrados (Moore, 1994), explicando a maior porcentagem destes na concentração fossilífera. A escassez de clavículas é devido à grande fragilidade desses elementos (Moore, 1994).
Metapodiais e tíbias são os mais completos no Lajedão do Patrício. A pequena superfície de impacto e tamanho dos metapodiais explica a excelente preservação, como em outros depósitos fossilíferos (Araújo-Júnior et al., 2012, 2013). Já a completude de tíbias é intrigante, devido a sua grande superfície de impacto e tamanho, o que as torna altamente susceptíveis à fragmentação durante a fase bioestratinômica, indicando proximidade entre local de acumulação e sítio de morte.

Ossos longos são os mais frequentes na 
acumulação $(60,4 \%)$, se comparados aos curtos $(22,5 \%)$ e planos $(17,1 \%)$. A grande proporção de ossos longos é atribuída a preservação dos elementos mais abundantes no esqueleto de vertebrados, como costelas (Moore, 1994), embora a fragmentação identificada possa ter inflacionado a proporção desses. Dentro da porcentagem de ossos longos obtidos nesta análise, a proporção de tíbias $(9,2 \%)$ e úmeros $(9,2 \%)$ é baixa, sugerindo ausência ou baixa influência de carnívoros/carniceiros no processo de acumulação. Soma-se a isto a ausência de alterações ósseas produzidas por tais agentes como: marcas de mordidas. Pois autos valores destes elementos na concentração fossilífera, indicam seleção e acumulação por carnívoros/carnívoros durante a fase bioestratinômica (Todd \& Rapson, 1988). Araújo-Júnior et al. (2013), identificaram valores similares, descartando estes agentes como responsáveis pela acumulação dos bioclastos, mesmo identificando alterações produzidas por carnívoros/carniceiros. Portanto, se esses fossem responsáveis pela concentração dos bioclastos, tais alterações seriam bem mais frequentes (Hutson, 2012).

No Lajedão do Patrício, elementos esqueletais com baixo valor de FTI são relativamente abundantes $(32,5 \%)$, sendo os de alto valor de FTI menos frequentes $(21,2 \%)$. Os elementos mais frequentes são aqueles com valor de FTI intermediário (46,5\%). O predomínio de bioclastos menos transportáveis indica curto transporte entre tanatocenose e tafocenose. Porém, os com alto FTI são representados, principalmente, por corpos vertebrais alterados devido ao transporte, indicando que foram ressedimentados ou retrabalhados de outras acumulações.

O predomínio de elementos dificilmente transportados com direção de paleocorrente corrobora a hipótese de que a acumulação analisada exibe características residuais (carga de fundo). A presença das três categorias de FTI, em menor proporção os com alto FTI, indica que o fluxo responsável pela acumulação e retrabalhamento teve capacidade de manter em transporte os ossos mais leves, mas não de eliminar por completo sua presença. Portanto, a associação fossilífera analisada representa uma acumulação gerada por processos fluviais (aluviais), baseando-se na equivalência hidráulica entre clastos e bioclastos, e domínio de baixo e moderado valores de FTI.

\section{Abrasão}

Abrasão é definida como o produto da interação dos bioclastos com o substrato, sedimentos e fluído. As feições de desgaste geradas por este processo são indicativas do tempo e intensidade de interação entre ossos e sedimentos, e não necessariamente produto da distância de transporte (Shipman, 1981). No Lajedão do Patrício, $41 \%$ dos bioclastos exibem pouco ou nenhum desgaste por abrasão (Figura 3B), 29\% apresenta desgaste moderado das extremidades (Figura 6C) e somente 3,7\% dos bioclastos apresentam intenso desgaste por abrasão (Figura 6E). Espécimes intensamente alterados por abrasão geralmente apresentam sinais extensivos de intemperismo.

O baixo a moderado grau de abrasão identificado é algo incomum para associações fossilíferas de carga de fundo, onde os processos operantes de transporte são tração e rolamento (FTI 2 e 3 ).

Tal fato indica improvável a ação de transporte extensivo, corroborando a hipótese de curto transporte (concentrações periféricas sensu Araújo-Júnior, 2016) entre área fonte (tanatocenose) e tafocenose. Também são identificadas feições abrasivas, como desgaste do tecido ósseo ao redor das epífises, que foram identificadas em tíbias e vértebras (Figura 6 A, D e F), devido ao rolamento durante o transporte. Assim, o desgaste incipiente das extremidades indica transporte curto entre tanatocenose e local de deposição final. Espécimes onde o tecido esponjoso está exposto é identificado o desgaste dos tecidos ósseos (polimento). Tal alteração é atribuída à interação entre fluido, sedimentos finos e bioclasto, durante exposição subaquosa (Figura 6G).

\section{Estágios de Intemperismo}

Das 108 amostras analisadas, 81,5\% (88 amostras) apresenta evidências de intemperismo. Dessas, 73 apresentam um único grau, sendo os estágios 1 e 2 os mais frequentes (Figura 7 A-D), indicando curto período de exposição subaérea (1 a 3 anos), de acordo com Behrensmeyer, (1978). Apenas 13 amostras apresentam estágio 3 (Figura $7 \mathrm{E}-\mathrm{F}$ ), indicando período moderado a longo (4 a 5 anos) de exposição subaérea (Behrensmeyer, 1978). Ao compararmos o perfil de intemperismo obtidos nesta análise (Figura 8), com os obtidos por Behrensmeyer (1978) para diferentes configurações ambientais (Figura 9). 
Observa-se que a tanatocenose que serviu com fonte dos bioclastos encontrados na tafocenose do Lajedão do Patrício, provavelmente apresenta configurações vegetacionais de florestas abertas. A divergência entre intemperismo e grau de articulação aponta controle das condições locais de temperatura e umidade, que influenciam diretamente o intemperismo dos ossos Cutler et al. (1999). Em ambientes com pouca variação destes fatores, os bioclastos apresentam baixo intemperismo, mesmo totalmente desarticulados, tal fato corrobora a hipótese de ambientes de florestas abertas evidenciado através do perfil de intemperismo obtidos para tafocenose analisada.

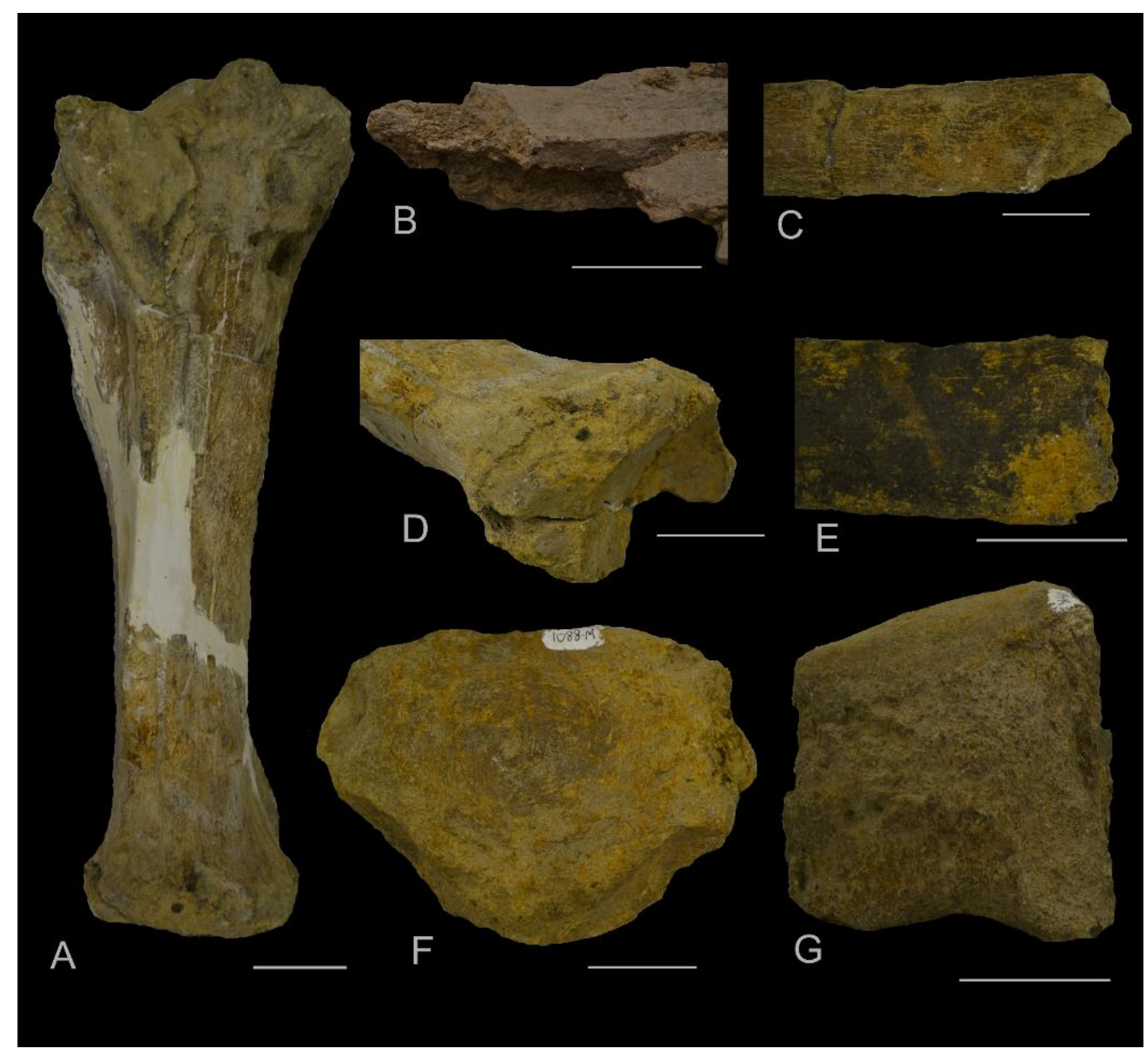

Figura 6 - A- tíbia de Notiomastodon platensis (UFRJ DG 1070-M; B- fragmento de diáfise (UFRJ DG 1141-M), com pouco ou nenhum desgaste das extremidades; C- fragmento de costela indet. (UFRJ DG 1126-M), com desgaste moderado das extremidades, D- visão detalhada de epífise distal do fóssil A; E- fragmento de costela indet. (UFRJ DG 1098-M) com a extremidade bem alterada; F- corpo vertebral de Notiomastodon platensis (UFRJ DG 1088-M), com sinais de desgaste devido ao rolamento; G- corpo vertebral indet. (UFRJ DG 1091-M), com sinais de desgaste devido à interação fluido e sedimentos. Escala em barra de $5 \mathrm{~cm}$.

As diferentes proporções dos estágios de intemperismo de Behrensmeyer (1978), indicam diferentes histórias tafonômicas durante $\mathrm{o}$ período de acumulação dos restos esqueletais de uma concentração fossilífera. No depósito fossilífero do Lajedão do Patrício é observado um perfil de intemperismo dominado pelos estágios 1 e 2, que são elementos pouco alterados.

A partir disto, é possível postular duas hipóteses: (1) os elementos esqueletais sofreram soterramento relativamente rápido; e (2) ou as configurações ambientais retardaram o processo de intemperismo. O depósito fossilífero do Lajedão do Patrício pode ser o resultado da segunda hipótese, pois apresenta elementos completos, fragmentados e desarticulados. Tais características observadas indicam que os bioclastos analisados sofreram exposição subaérea por tempo relativamente longo.

O restante (15 amostras) apresenta dois estágios de intemperismo (Figura 7 G-M). O 
intemperismo diferencial entre superfície superior (MWS), e inferior em contato com solo (FWS) indica a estabilidade dos bioclastos antes do soterramento final (Byers, 2002). Ossos com MWS (estágio 2) e FWS (estágio 1) estão sujeitos a pouco ou nenhum deslocamento (estáveis), já elevado estágio em ambas as superfícies indica sucessivos deslocamentos, representando instabilidade (Byers, 2002). A presença de elementos instáveis e estáveis na acumulação fossilífera aponta a ocorrência de mais de uma fase de transporte e acumulação dos bioclastos analisados que compõem a tafocenose do Lajedão do Patrício.

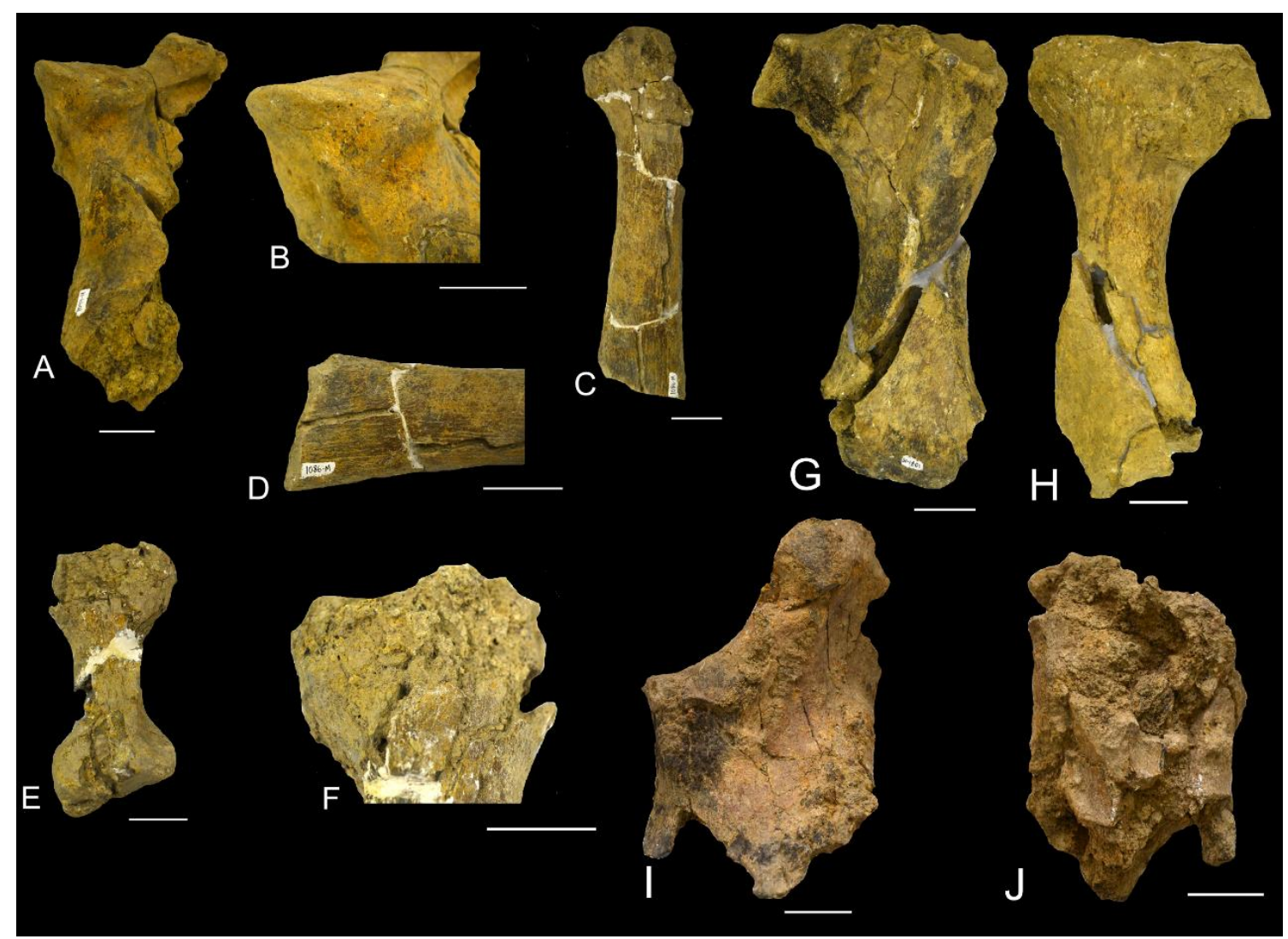

Figura 7 - A) Ulna fragmentada de Glyptodon (UFRJ DG 1094-M) com estágio 1; B- o mesmo fóssil em detalhe; C) Clavícula de Notiomastodon platensis (UFRJ DG 1086-M) no estágio 2; D) mesmo fóssil em detalhe; E) Metacarpo de Eremotherium laurillardi (UFRJ DG 1095-M) no estágio 3; F- o mesmo fóssil em detalhe; G) Tíbia de Eremotherium laurillardi (UFRJ DG 1071-M) no estágio 1; H) o mesmo fóssil com estágio 2; I) Epífise proximal indet (UFRJ DG 1120 M) no estágio $2 ; \mathbf{J}$ ) mesmo fóssil no estágio 4 . Escala em barra de $5 \mathrm{~cm}$.

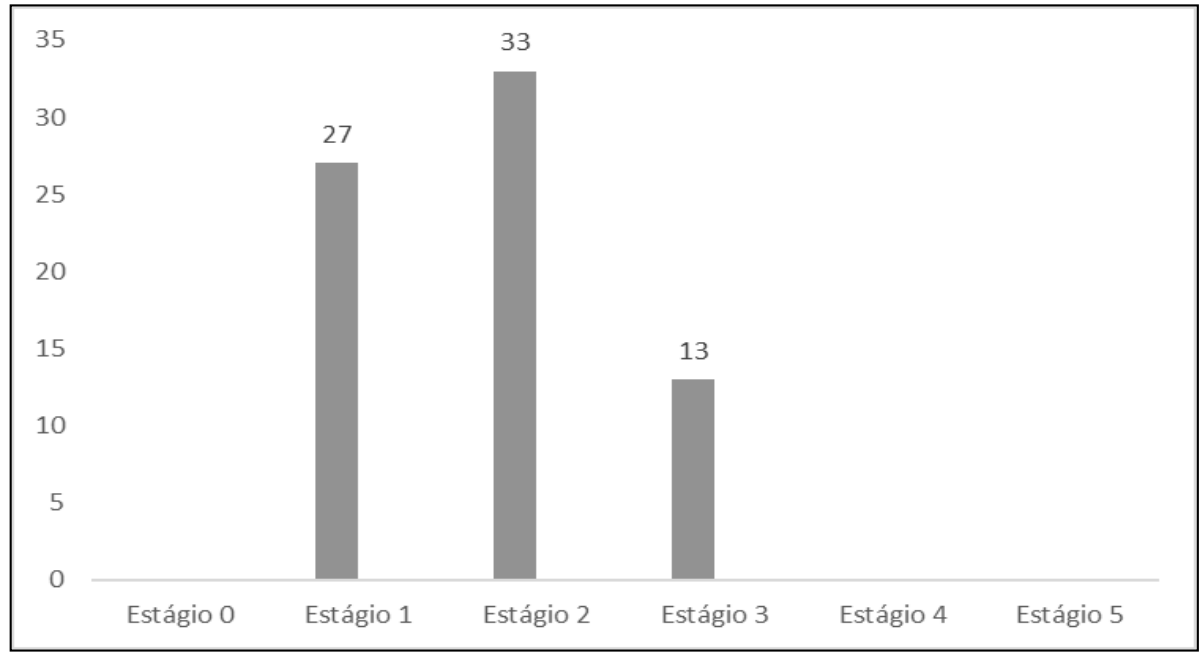

Figura 8 - Gráfico exibindo a quantidade de amostras em cada estágio de intemperismo (Behrensmeyer, 1978).

\section{Tipos de Quebra}

Das amostras analisadas, $42 \%$ apresentam tipos de quebra de acordo com a proposição de Shipman (1981). Dentre os tipos identificados, 
observa-se o predomínio de quebra pósfossilização em $44 \%$ das amostras (Figura 10A, B). Quebra perpendicular à diáfise e colunares apresentam a mesma proporção (22\%) (Figura 10D - F). Quebra do tipo espiral (Figura 10C) também são observadas, correspondendo a $11 \%$ das quebras. Consensualmente, quebras pósfossilização são geradas depois da fossilização, indicando fases de retrabalhamento dos restos esqueletais durante a acumulação (Shipman, 1981; Cladera et al., 2004).

Em depósitos do Nordeste brasileiro quebras pós-fossilização aparecem em grande proporção (Araújo-Júnior et al., 2013, 2015; Ribeiro, 2014), interpretadas como resultantes de eventos de retrabalhamento. Em depósitos fluviais, Kerber \& Oliveira (2008) e Tomassini \& Montalvo (2013) relatam as mesmas características, atribuindo-as ao retrabalhamento de tafocenoses de planície de inundação e do próprio canal. Portanto, a fragmentação identificada nessas acumulações fossilíferas é característica intrínseca aos processos sedimentares desses ambientes deposicionais.
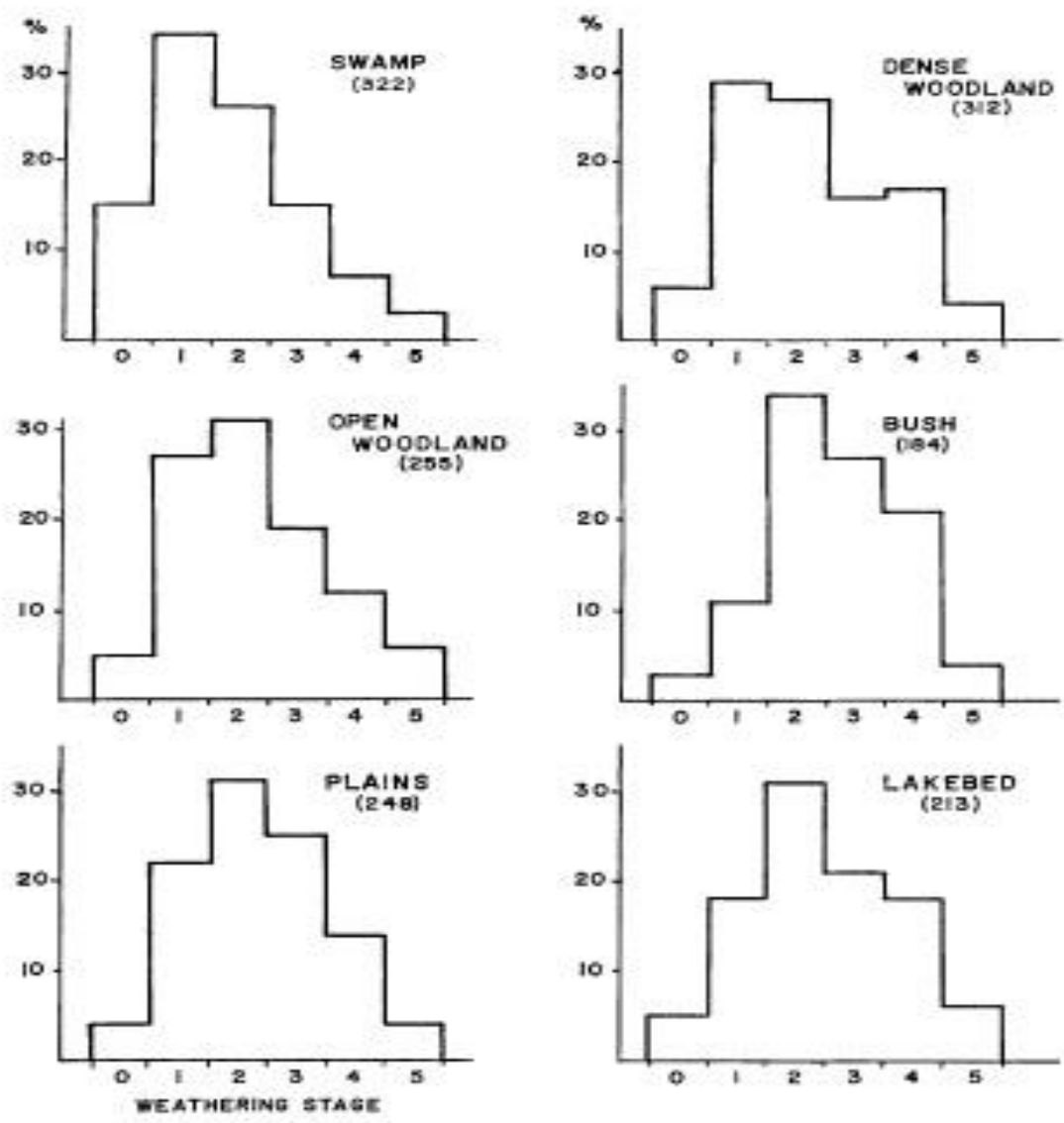

Figura 9 - Perfis de intemperismo obtidos por Behrensmeyer (1978), para diferentes configurações ambientais (extraído de Behrensmeyer, 1978).

Os demais padrões de quebra identificados são originados durante a fase bioestratinômica, e são divididas em duas classes: seca e fresca (Villa \& Mahieu, 1991). Quebras secas são perpendiculares, oblíquas e longitudinais, geradas devido à longa exposição subaérea dos ossos, associadas à oscilação de temperatura e umidade (Garcia et al., 2006). Já padrões colunares e espirais são quebras frescas possivelmente associadas à atividade biológica (carnívoros/carniceiros) (Shipman, 1981; Garcia et al., 2006). A ausência de feições que caracterizam a ação de carnívoros/carniceiros descarta a ação destes no processo de fragmentação dos bioclastos analisados.

\section{Feições Biogênicas}

Evidências de pisoteio (trampling) e alterações ósseas geradas por carnívoros/carniceiros não foram observadas. Bioerosões geradas por invertebrados também não foram identificadas. $\mathrm{A}$ ausência destas modificações indica breve exposição da tanatocenose antes do soterramento (Kaiser, 2000), ou então que foram obliteradas. A presença de marcas de dissecação, abrasão e alta fragmentação corroboram o último cenário. $\mathrm{Na}$ concentração fossilífera do Lajedão do Patrício são identificadas modificações ósseas geradas 
por raízes (Figura 11E e G). Os bioclastos apresentam raízes anexadas à superfície óssea, sendo geradas pelo crescimento de plantas atuais na área do depósito fossilífero (Figura 1B, C), sendo consideradas alterações pós-soterramento.

\section{Alterações Pós-Soterramento}

Estas são de origem física, química e biológica. As físicas são relacionadas ao peso dos sedimentos sobrejacentes, devido à compressão litostática (Cladera et al., 2004). Das 108 amostras analisadas, 26 apresentam danos atribuídos à sobrecarga de sedimentos (Figura $11 \mathrm{~A}$ e E). Outro agente pós-soterramento responsável pela alteração dos bioclastos analisados é atividade de raízes de vegetação atual (biológica). As raízes ao procurarem recursos minerais penetram nos bioclastos provocando fragmentação e desmineralização do tecido esponjoso. A desmineralização provavelmente está associada ao ataque de ácidos orgânicos produzidos pelas raízes na busca por nutrientes. A ação de raízes é o principal agente de alteração pós-soterramento. Isto se deve ao achado de grande quantidade de raízes no interior dos ossos durante a restauração (60\% do material).

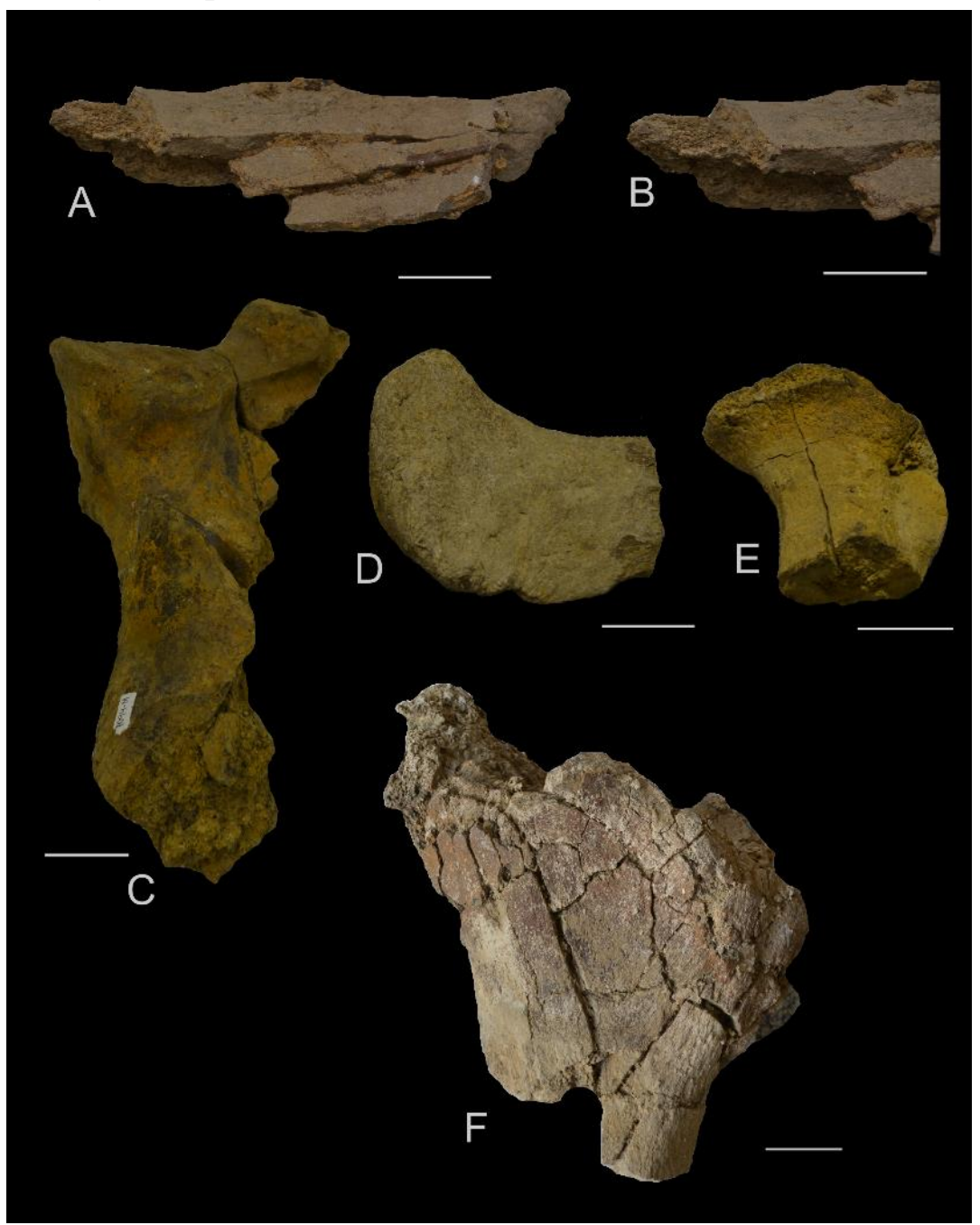

Figura 10 - A- fragmento indeterminado (UFRJ DG 1141-M) com quebra pós-fossilização; B- mesmo fóssil em detalhe; C- ulna de Glyptodon fragmentada (UFRJ DG 1094-M) mostrando quebra espiral; D- fragmento de escápula de Eremotherium laurillardi (Am- 03) com quebra perpendicular; E- mesmo fóssil em detalhe; F- epífise proximal de tíbia de Eremotherium laurillardi ( Am-22) apresentando quebra colunar. Escala em barra de $5 \mathrm{~cm}$.

Outra feição identificada é o revestimento da superfície dos restos esqueletais por impregnação de material carbonático (química). O material que reveste a superfície é oriundo do intemperismo químico de rochas carbonáticas mais antigas da bacia sedimentar do Irecê (Figura 11B, C, D e F).
Casal et al. (2014) relatam que a precipitação deste material indica período de aridez, gerado pelo déficit hídrico e consequente precipitação de solutos carbonáticos.

\section{Taphorecords}

$\mathrm{Na}$ tafonomia este conceito é utilizado para obter uma cronologia relativa de deposição dos 
restos esqueletais (Zunino et al., 2012). Estes são caracterizados a partir de alterações (macroscópicas) dos restos esqueletais, sejam elas bioestratinômicas e diagenéticas. As alterações ósseas utilizadas para a classificação dos diferentes taphorecords (TR), são: estágio de intemperismo, abrasão e incrustação por calcita. A partir disto foram estabelecidas quatro classes de taphorecords, que são;

Taphorecords I: espécimes estão pouco alterados ou inalterados pelos agentes destrutivos. Estes apresentam estágio de intemperismo 1, abrasão não é observado;

Taphorecords II: espécimes apresentam grau de intemperismo 2, ou diferentes estágios de intemperismo na superfície óssea (Byers, 2002).
A superfície em contato com o solo (FWS: flipside weathering stage) com grau de intemperismo 1, e superior (MWS: máximum weathering stage) no estágio 2. Pouca alteração por abrasão é identificada;

Taphorecords III: espécimes apresentam estágio de intemperismo 3, ou diferentes graus de intemperismo: FWS pode apresentar estágios $2 \mathrm{e}$ 3, e MWS atinge os estágios 4 e 5 de intemperismo. Abrasão moderada a intensa;

Taphorecords IV: espécimes neste grupo exibem a superfície óssea revestida ou parcialmente revestida (área maior ou igual a $25 \%$ ), por carbonato de cálcio (calcita). Nos que apresentam a superfície parcialmente revestida o intemperismo não foi critério de avaliação.

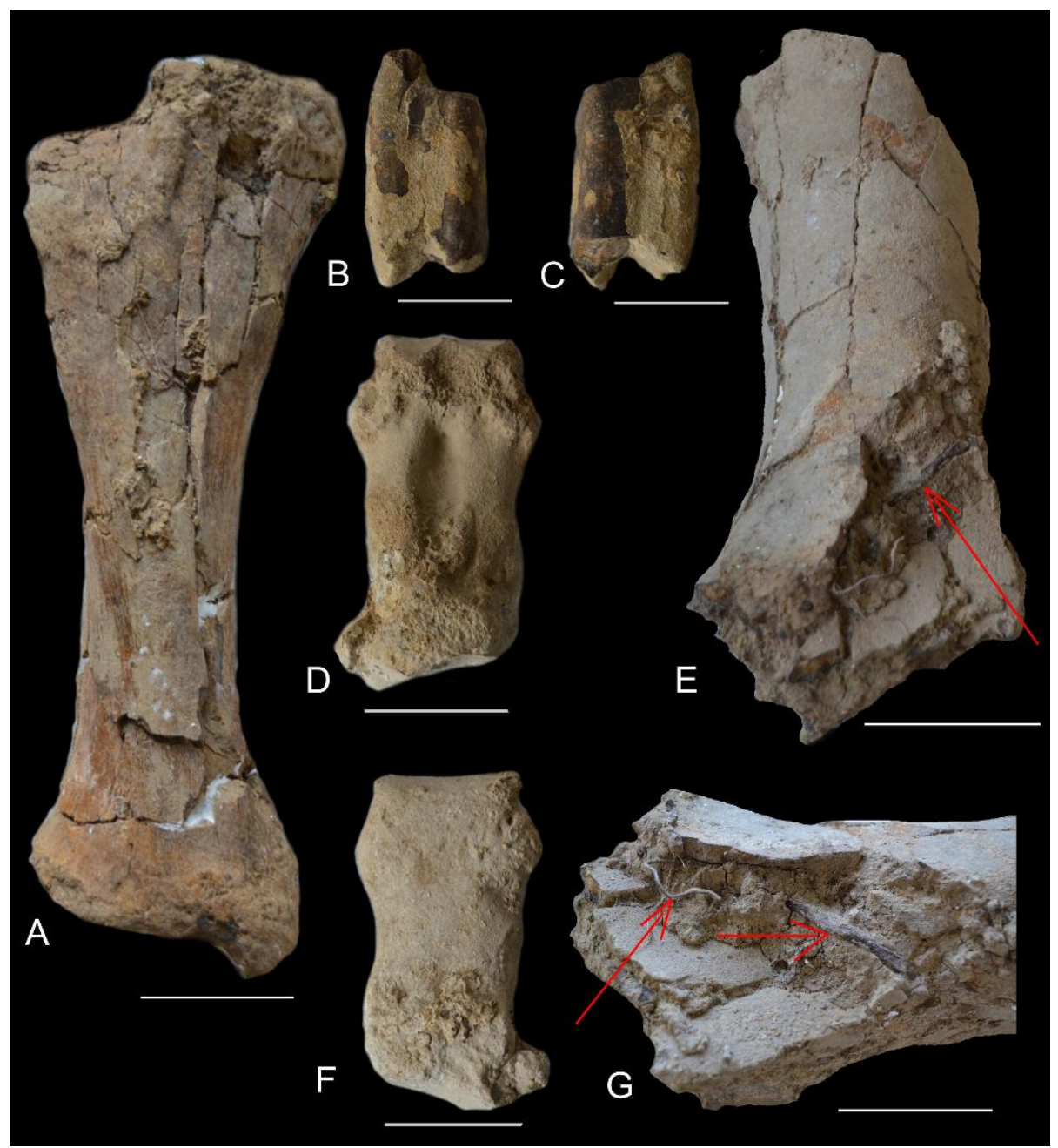

Figura 11 - A) tíbia de Notiomastodon platensis com rachaduras pós-soterramento (Am- 29); B e C) dentes de Eremotherium laurillardi (Am- 20); D e F) metacarpo de Notiomastodon platensis com revestimento da superfície (Am04); E e G) fragmento de rádio de Notiomastodon platensis com raízes anexadas. Escala em barra de $5 \mathrm{~cm}$.

A presença das quatro classes de TR estabelecidas no depósito fossilífero do Lajedão do Patrício indica uma complexa história tafonômica (Figura 12), devido à presença de ossos com distintas histórias de acumulação na mesma acumulação fossilífera. Através destes foi possível, do ponto de vista tafonômico classificálos em: acumulados, ressedimentados e reelaborados (Fernandez-López, 2011).

Espécimes pertencentes aos TR I são classificados como ossos acumulados. Já os bioclastos que estão enquadrados dentro dos TR 
II e III são classificados como ressedimentados, e bioclastos no taphorecords IV como retrabalhados. Bioclastos que apresentam TR I são depositados no mesmo evento de acumulação e soterramento, pois apresentam a superfície óssea pouco alterado por processos tafonômicos. Os restos esqueletais que apresentam características do TR II e III são transportados junto com espécimes do TR I, porém são soterrados parcialmente ou não, devido a presença de diferentes estágios de intemperismo na superfície óssea. Os ossos com características dos TR II e III apresentam diferentes histórias tafonômicas, pois os restos esqueletais enquadrados no TR III apresentam modificações da superfície óssea que indicam maior período de exposição subaérea que bioclastos com TRII. Estas diferentes histórias sedimentares baseiamse nos diferentes estágios de intemperismo identificados. A evidência de retrabalhamento do TR IV é suportada pelo revestimento da superfície óssea, indicando que estes já tinham sofrido algum processo de fossilização antes de serem acumulados e soterrados, junto com bioclastos que não apresentam tal alteração óssea.

A presença de conjuntos fósseis com características tafonômicas distintas, indica que o jazigo fossilífero do Lajedão do Patrício é uma acumulação do tipo attritional. Estas são formadas pelo acúmulo de carcaças ao longo do tempo, com forte controle dos processos sedimentares e do ambiente deposicional (Alberdi et al., 2001). A identificação dos diferentes taphorecords no mesmo nível fossilífero analisado, legitima a hipótese de acumulação afetada por fases de acumulação, ressedimentação e reelaboração.

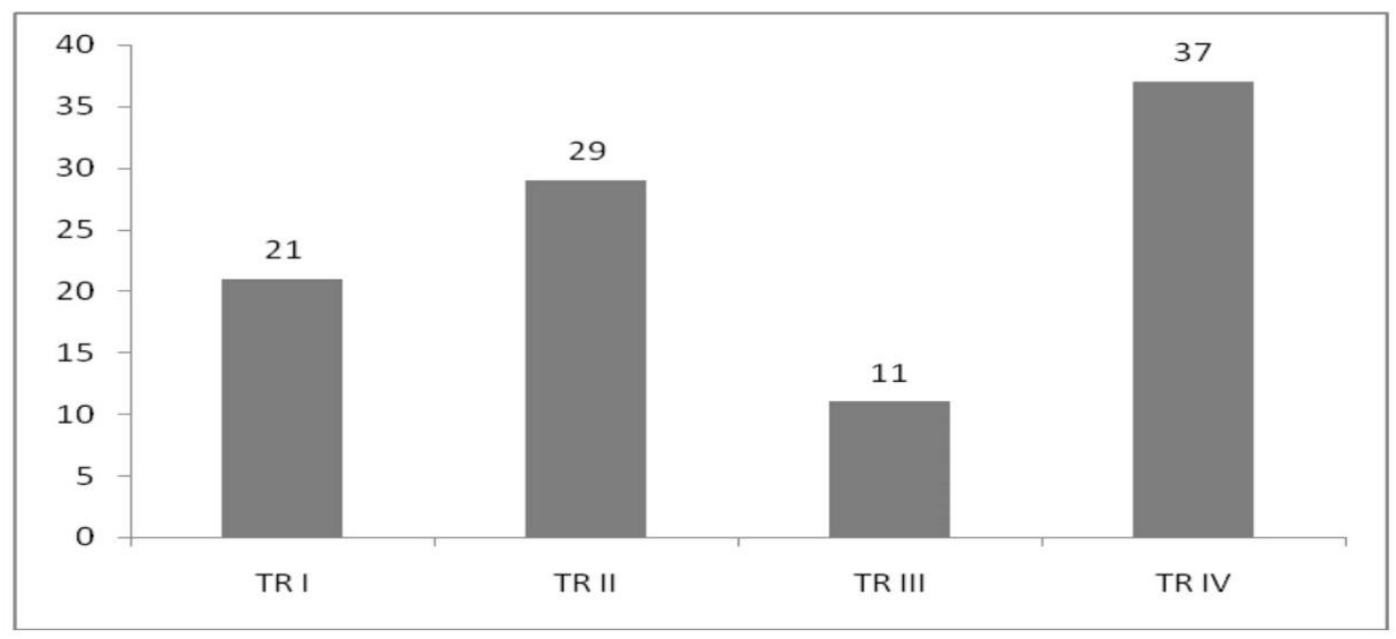

Figura 12 - Abundância relativa dos taphorecords (TR I-IV) na concentração fossilífera.

\section{INTERPRETAÇÃO TAFONÔMICA}

O agente responsável pelo transporte, retrabalhamento e acumulação dos restos esqueletais analisados, é atribuído a eventos de enchentes relâmpagos em drenagens temporárias, numa paisagem geomorfológica aplainada da bacia sedimentar do Irecê. Esses fluxos transportaram, através do tempo, carcaças oriundas de tanatocenoses próximas, na área de abrangência NW a WSW, e retrabalharam restos esqueletais previamente soterrados. A ciclicidade dos eventos de input de novas carcaças, junto a episódios de retrabalhamento, resultou na mistura de elementos não contemporâneos (mistura temporal), fato também observado por Araújo-Júnior et al. (2013, 2015) e Ribeiro (2014). Embora todas as evidências indiquem mistura temporal durante a formação da concentração fossilífera, esta informação só pode ser quantificada através de datações absolutas.

Através das análises de FTI e orientação dos bioclastos que compõem a concentração fossilífera, pode-se afirmar que esta foi gerada por fluxos trativos que transportaram e acumularam bioclastos e clastos. Estes fluxos, ao atingirem a depressão onde se localiza a acumulação fossilífera, sofreram desaceleração, depositando os elementos mais densos, mas com energia suficiente para manter em transporte os menos densos. A ausência de elementos articulados, a alta proporção de bioclastos fragmentados no Lajedão do Patrício e feições tafonômicas de ambientes de alta energia é indicativo de ambiente de canal. A alteração da fidelidade taxonômica entre biocenose e tafocenose do Lajedão do Patrício é o resultado de 
eventos de ressedimentação e retrabalhamento por ação fluvial durante a formação do depósito fossilífero. Características similares são identificadas por outros autores (Longrich \& Currier, 2009b; Brown et al., 2013), também atribuídas a fases de transporte e retrabalhamento por ação fluvial durante o período de acumulação.

Ao compararmos diferentes concentrações fossilíferas do Nordeste brasileiro (Araújo-Júnior et al., 2013, 2015; Ribeiro, 2014; Silva, 2008; Alves et al., 2007), com padrões tafonômicos e sedimentares semelhantes, sendo o padrão distintivo entre elas o tipo de transporte (Tabela 2). Tais padrões tafonômicos e sedimentares obser- vados podem indicar possíveis superfícies de descontinuidade associadas a hiatos deposicionais. Para a confirmação de tal hipótese é necessário um maior detalhamento tafonômico dos depósitos fossilíferos do Quaternário do Nordeste. Portanto, as assinaturas tafonômicas observadas nos trabalhos citados acima e a distribuição geográfica das concentrações esqueletais comparadas tem um importante significado paleoambiental para o Quaternário. De uma perspectiva tafonômica Kidwell (1991) propõe que acumulações fossilíferas como as citadas acima, são do tipo attritional, fruto de mistura temporal de maior ou menor grau, o que irá depender da duração do hiato deposicional.

Tabela 2 - Aspectos tafonômicos e sedimentares de concentrações fossilíferas do Nordeste do Brasil, segundo Ribeiro (2014), Alves (2007), Silva (2001 e 2008), Faria (2016) e Araújo-Júnior et al. (2013 e 2015).

\begin{tabular}{l|c|c|l|c|c|c|c}
\hline Sítio Paleontológico & $\begin{array}{c}\text { Tipo de } \\
\text { transporte }\end{array}$ & $\begin{array}{c}\text { Empacota } \\
\text { mento }\end{array}$ & $\begin{array}{l}\text { Diversidade } \\
\text { de espécies }\end{array}$ & $\begin{array}{c}\text { Ambiente } \\
\text { deposicional }\end{array}$ & $\begin{array}{c}\text { Integridade } \\
\text { física }\end{array}$ & $\begin{array}{c}\text { Camada } \\
\text { sedimentar }\end{array}$ & $\begin{array}{c}\text { Mistura } \\
\text { Temporal }\end{array}$ \\
\hline $\begin{array}{l}\text { Quixabeira b } \\
\text { (Alves, et al., 2007) }\end{array}$ & Enxurradas & Moderado & Multitáxica & $\begin{array}{c}\text { Tanque (Planício } \\
\text { aluvio-coluvionar) }\end{array}$ & $\begin{array}{l}\text { Fragmentados/ } \\
\text { desarticulados }\end{array}$ & conglomerado \\
\hline $\begin{array}{l}\text { Brejo Madre de Deus } \\
\text { (Silva, 2001; 2008) }\end{array}$ & Enxurradas & Densamente & Paucitáxica & $\begin{array}{c}\text { Tanque (Aluvio- } \\
\text { Coluvionar) }\end{array}$ & $\begin{array}{l}\text { Fragmentados/ } \\
\text { Desarticulados }\end{array}$ & conglomerado \\
\hline $\begin{array}{l}\text { Lagoa do Rumo } \\
\text { (Ribeiro, 2014) }\end{array}$ & $\begin{array}{c}\text { Fluxo de } \\
\text { detritos }\end{array}$ & Densamente & Paucitàxica & $\begin{array}{c}\text { Tanque (Alúvio- } \\
\text { Coluvionar) }\end{array}$ & $\begin{array}{l}\text { Fragmentados/ } \\
\text { Desarticulados }\end{array}$ & Conglomerado \\
$\begin{array}{l}\text { Lajedão do Patrício } \\
\text { (Faria, 2006) }\end{array}$ & Enxurradas & Densamente & Paucitàxica & Fluvial & $\begin{array}{c}\text { Fragmentado/ } \\
\text { Desarticulados }\end{array}$ & Conglomerado \\
\hline $\begin{array}{l}\text { Curimatãs (Araújo- } \\
\text { Júnior et al., 2015) }\end{array}$ & Enxurradas & Xultitáxica & Tanque (Fluvial) & $\begin{array}{l}\text { Fragmentados/ } \\
\text { desarticulados }\end{array}$ & Conglomerado \\
\hline $\begin{array}{l}\text { Jiráu (Araújo-Júnior } \\
\text { et al., 2013) }\end{array}$ & $\begin{array}{c}\text { Fluxo de } \\
\text { detritos }\end{array}$ & Densamente & Multitàxica & $\begin{array}{c}\text { Tanque (Aluvio- } \\
\text { Coluvionar) }\end{array}$ & $\begin{array}{l}\text { Fragmentados/ } \\
\text { Desarticulados }\end{array}$ & Conglomerado & $\mathbf{X}$ \\
\hline
\end{tabular}

\section{CONCLUSÕES}

Pode-se concluir que a presença de megamamíferos e a ausência de pequenos vertebrados no Lajedão do Patrício ocorrem em função do tendencialmente tafonômico por processos sedimentares, devido à grande resistência de ossos de grandes animais aos agentes destrutivos (bióticos e abióticos). A ampla presença de ossos de Eremotherium laurillardi é indicativa de abundância da espécie em biocenoses e a resistência de seus restos esqueletais como mencionado anteriormente

Os diferentes estágios de intemperismo e taphorecords identificados refletem condições de acumulação attritional. As tanatocenoses que serviram de fonte ficaram tempo suficientemente expostas para total desarticulação, com forte influência das condições ambientais e de transporte.

A característica residual da acumulação fossilífera do Lajedão do Patrício, confirma a ideia de curto transporte entre a área fonte (tanatocenose) e local de acumulação e soterramento. Assim, pode-se afirmar a característica periférica (sensu Araújo-Júnior, 2016). Outras feições tafonômicas (ex: carnívoros/carniceiros) provavelmente foram obliteradas durante o período de acumulação, devido a sucessivos eventos de ressedimentação e retrabalhamento.

A utilização dos taphorecords foi de fundamental importância, pois através destes foi possível definir grupos com histórias tafonômicas distintas, evidenciando eventos de ressedimentação e retrabalhamento durante a formação do depósito fossilífero. Portanto, a abordagem tafonômica dos ossos como partículas sedimentares é de fundamental importância, na medida em que os processos de alteração da superfície óssea e de acumulação são fortemente controlados pelos processos sedimentares e ambientes de deposição. Deste modo, podemos afirmar que a tafocenose do Lajedão do Patrício é fruto de processos sedimentares, onde esta foi gerada pelo input de novas carcaças somada a erosão e exumação de bioclastos já soterrados. Behrensmeyer \& Chapman (1993) relatam que tafocenoses deste tipo são geradas por hiatos deposicionais, que criam condições de baixo aporte de material siliciclástico em relação a bioclastos.

A partir dos dados obtidos é proposto o enquadramento da concentração fossilífera do 


\section{AGRADECIMENTOS}

Os autores externam seus agradecimentos à CAPES (Coordenação de Aperfeiçoamento de Pessoal de Nível Superior), CNPq (Conselho Nacional de Desenvolvimento Científico e Tecnológico) e FAPERJ (Fundação Carlos Chagas Filho de Amparo à Pesquisa do Estado do Rio de Janeiro) pelo apoio financeiro, e Secretaria Municipal de Meio Ambiente de João Dourado, pelo apoio de infraestrutura na realização das atividades de escavação. Ao Prof. Dr. Hermínio Ismael de AraújoJúnior, pela revisão detalhada do manuscrito..

\section{REFERÊNCIAS}

ALBERDI, M.T.; ALONSO, M.A.; AZANZA, B.; HOYOS, M.; MORALES, J. Vertebrate taphonomy in circum-lake enviroments three cases in the Guadix-Baza Basin (Granda Spain). Paleogeography, Paleoclimatology, Paleoecology, v. 165 , n. 1-2, p. 1-26, 2001

ALVES, R.S.; BARRETO, A.M.F.; BORGES, L.E.P.; FARIAS, C.C. Aspectos tafonômicos no depósito de mamíferos pleistocênicos de Brejo Madre de Deus, Pernambuco. Estudos Geológicos, v. 17, p. 114-122, 2007.

ARAÚJO-JÚNIOR, H.I. \& MARINHO, T.S. Taphonomy of a baurusuchus (Crocodyliformes, Baurusuchidae) from the Adamantina formation (Upper Cretaceous, Bauru Basin), Brasil: Implications for preservational modes, time resolution and paleoecology. Journal American Earth Science, v. 47, p. 90-99, 2013.

ARAÚJO-JÚNIOR, H.I. \& PORPINO, K.O. Assembleias fossilíferas de mamíferos do Quaternário do Estado do Rio Grande do Norte, Nordeste do Brasil: diversidade e aspectos tafonômicos e paleoecológicos. Pesquisas em Geociências, v. 38, p. 67-83, 2011.

ARAÚJO-JÚNIOR, H.I. Classifying vertebrate assemblages preserved in Quaternary tank deposits: Implications for vertebrate taphonomy and paleoecology. Paleogeography, Paleoclimatology, Paleoecology, v. 445, p. 147-152, 2016.

ARAÚJO-JÚNIOR, H.I.; PORPINO, K.O.; BERQVIST, L.P. Vertebrate taphonomy and paleocology in na Upper Pleistocene tank deposit of Paraíba, Brazil: Taphonmic modes, evidence of temporal and spatial resolutions and paleoecological patterns of the Brazilian Intertropical Region. Paleogeography, Paleoclimatology, Paleoecology, v. 437, p. 1-17, 2015.

ARAÚJO-JÚNIOR, H.I.; PORPINO, K.O.; XIMENES, C.L.; BERQVIST, L.P. Análise multivariada como ferramenta tafonômica no estudo das associações quartenárias de mamíferos do Nordeste do Brasil. Gaea - Journal of Geoscience, v. 7, p. 104-111, 2011.

ARAÚJO-JÚNIOR, H.I.; PORPINO, K.O.; XIMENES, C.L.; BERQVIST, L.P. Unveiling the taphonomy of elusive natural tank deposits: A study case in the Pleistocene of northeastern Brazil. Paleogeography, Paleoclimatology, Paleoecology, v. 378, p. 52-74, 2013.

ARAÚJO-JÚNIRO, H.I.; BISSARO-JÚNIOR, M.C.; SANTOS, T.T.; ALVES, R.S.; BERQVIST, L.P. Tafonomia da megafauna pleistocênica brasileira: Fluvial Transport Index (FTI) em análises de representatividade óssea. Revista Brasileira de Paleontologia, v. 15, p. 95-104, 2012.

ARRIBAS, A. \& PALMQVIST, P. Taphonomy and paleoecology of na assemblage of large mammals: hyaenid activity in the lower Pleistocene site at Venta Micena (Orce, Guadix-Baza, Granada, Spain). Geobios, v. 31, p. 3-47, 1998.

AULER, A.S.; PILÓ, L.B.; SMART, P.J.; WANG, X.; HOFFMANN, D.; RICHARDS, D.A.; EDWARDS, R.L.; NEVES, W.A.; CHENG, H. U-series dating and taphonomy of Quaternary vertebrates from Brazilian caves. Paleogeography, Paleoclimatology, Paleoecology, v. 240, p. 508-522, 2006.
BADGLEY, C. Counting individuals in mammalian fóssil assemblages from fluvial environments. Palaios, v. 1, p. 328-338, 1986. BEHRENSMEYER, A.K. \& CHAPMAN, R.E. Models and simulations of time-averaging in terrestrial vertebrate accumulations. In: KIDWELL, S.M., BEHRENSMEYER, A.K. (eds) Taphonomic approaches to time resolution in fóssil assemblages. Paleontological Society short course in paleontology. University of Tennessee, Knoxville, n. 6. p. 125-149, 1993.

BEHRENSMEYER, A.K. Taphonomic and ecologic sedimentological and paleontological features of Late information from bone weathering. Paleobiology, v. 4, p. 150-162, 1978.

BEHRENSMEYER, A.K. Terrestrial vertebrate accumulations. In: P.A. ALLISON \& D.E.G. BRIGGS (ed.) Taphonomy: Releasing the Data Locked in the Fossil Record. Plenum Press, New York, p. 291-335, 1991.

BEHRENSMEYER, A.K. The taphonomy and paleoecology of Plio-Pleistocene vertebrate assemblages of Lake Rudolf, Kenya. Bull. Mus. Comp. Zool., v. 146, p. 473 578, 1975.

BEHRENSMEYER, A.K.; WILLIS, B.J.; QUADE, J. Floodplains and palesols of Pakistan Neogene and Wyoming Paleogene deposits: a comparative study. Paleogeography, Paleoclimatology, Paleocology, v. 115, p. 37-60, 1995.

BERQVIST, L.P. \& ALMEIDA, E.B. Biodiversidade de mamíferos fósseis brasileiros. Geociências, v. 9, p. 54-68, 2004.

BERQVIST, L.P.; ALMEIDA, E.B.; ARAÚJO-JÚNIOR, H.I. Tafonomia da assembleia fossilífera de mamíferos da "Fenda 1968", Bacia de São José de Itaboraí, Estado do Rio de Janeiro, Brasil. Revista Brasileira de Paleontologia, v. 14, p. 75-86, 2011 BERTONI-MACHADO, C.; SOARES, M. B.; KISLOWSKI, F.F.; DENTZIEN-DIAS, P.C. Uma Peculiar Tafocenose Controlada por Ação Biogênica no Triássico Médio do Rio Grande do Sul, Brasil. Pesquisas em Geociências, v. 35, p. 57-69, 2008.

BROWN, C.M.; EVANS, D.C.; CAMPIONE, N.E.; O'BRIEN, L.J.; EBERTH, D.A. Evidence for taphonomic size bias in the Dinosaur Park Formation (Campanian, Alberta), a model Mesozoic terrestrial alluvial-paralic system. Paleogeography, Paleoclimatology, Paleoecology, v. 372, p. 108-122, 2013.

BYERS, D.A. Taphonomic analysis, associational integrity and depositional history of the Fertternan mammoth, eastern Wyoming, U.S.A. Geoarchaeology, v. 17, p. 417- 440, 2002.

CARTELLE, C. Edentata e megamamíferos herbívoros extintos da Toca dos Ossos (Ourolândia, BA, Brasil). Belo Horizonte, 1992. 700 p. Tese (Doutorado em Geociências) Universidade Federal de Minas Gerais.

CARTELLE, C. Pleistocene mammals of the Cerrado and Caatinga of Brazil, in: EISENBERG, J.F. \& REDFORD, K.H. (eds.), Mammals of the Neotropics: The Central Neotropics. The University of Chicago Press, Chicago, p. 27-46, 1999.

CASAL, G.A.; IBIRICU, L.M.; ALLARD, J.O.; MARTÍNEZ, R.D.; LUNA, M.; RIGA, B.J. G. Tafonomía del titanosaurio Aeolosaurus colhuhuapensis, Cretácico Superior, Patagonia central, Argentina: um ejemplo de preservación em fácies fluviales de desbordamiento. Revista Mexicana de Ciencias Geológicas, v. 21, n. 2, 163-173, 2014. 
CLADERA, G.; RUIGOMEZ, E.; ORTIZ-JAUREGUIZAR, E.; BOND, M.; LÓPEZ, G. Tafonomía de La Gran Hondonada (Formación Sarmiento, Edad-Mamífero Mustersense, Eoceno Mádio), Chubut, Argentina. Ameghiniana, v. 41, p. 315-330, 2004.

CPRM - COMPANHIA DE PESQUISA DE RECURSOS MINERAIS. Projeto Bacia de Irecê, Relatório Final, v. 1, 150p., 1985.

CUTLER, A.H.; BEHRENSMEYER, A.K.; CHAPMAN R.E. Environmental information in a recent assemblage roles of taphonomic processes and ecological change. Paleogeography, Paleoclimatology, Paleoecology, v. 149, n. 1-4, p. 359-372, 1999.

DANTAS, M.A.T.; ZUCON, M.H.; RIBEIRO, A.M. Megafauna pleistocênica da Fazenda do Elefante, Gararu, Sergipe, Brasil. Geociências, v. 24, p. 277-287, 2005.

EBERTH, D.A.; ROGERS, R.R.; FIORRILO, A.R. A practical approach to the study of bonébeds. In: Rogers, R. R., Eberth, D. A., Fiorillo A. R. (Coords), Bonebeds: Genesis, Analysis and Paleobiological Significance. The University of Chicago Press, Chicago, p. 265-332, 2007a.

EBERTH, D. A.; SHANNON, M.; NOLAND, B.G. A bonebeds database: classification, biases and patterns of occurrence. In: ROGERS, R. R., EBERTH, D. A., FIORILLO, A. R. (Coords), Bonebeds: Genesis, Analysis and Paleobiological Significance. The University of Chicago Press, Chicago, p., 103-220, 2007b.

FERNÁNDEZ-LÓPEZ, S.R. Unidades registráticas, biocronología y geocronologia. Revista Española de Paleontologia, v. 2, p. 65-85, 1987.

FERNÀNDEZ-LÓPEZ, S.R. Taphonomic analysis and sequence stratigraphy of the Albarracinites beds (lower Bajocian, Iberian Range, Spain). An example of shallow condensed section. Bulletin de La Société Géologique de France, v. 182, p. 405-415, 2011.

FRISON, G.C. \& TODD, L.C. (Coords) Mammoth Site: Taphonomy and Archeology of a Clovis Kill in Northern Wyoming. University of New Mexico Press, Albuquerque, 200 p., 1986.

GARCIA, V.A.; EGIDO, R.B.; DEL PINO, J.M.B.; RUIZ, A.B.C.; APARÍCIO, L.F.; CALLEJA, S.H.; JIMENEZ, A.I.; GONZALES, M.M. Determinación de proceses de fractura sobre huesos frescos: Um sistema de análisis de los ângulos de los planos de fracturación como discriminador de agentes bióticos. Trabajos de Prehistoria, v. 63, n. 1, p. 37-45, 2006.

HOLZ, M. \& SIMÕES, M.G. (Coords). Elementos Fundamentais de Tafonomia. Editora da Universidade/ UFRGS, Porto Alegre, p. 79, 2002.

HOLZ, M. \& SOUTO-RIBEIRO, A. Taphonomy of the SouthBrazilian Triassic vertebrates. Revista Brasileira de Geociências v. 30, p. 491-494, 2000.

HOLZ, M.; SOARES, M.B.; SOUTO-RIBEIRO, A.W. Tafonomia de vertebrados: decifrando a gênese das ocorrências fossilíferas Permianas e Triássicas da Bacia do Paraná no Rio Grande do Sul. In: HOLZ, M.; DEROS, L.F. (Coords). Paleontologia do Rio Grande do Sul. Porto Alegre, UFRGS, CIGO, p. 44-66, 2000.

HUTSON, J.M. Neotaphonomic measures of carnivore serial predation at Ngamo Pan as na analog for interpreting open-air fauanl assemblages. Journal of Archeological Science v. 39, p. 440-457, 2012.

KAISER, J.M. Proposed insect modification to fóssil mammalian boné from Plio-Pleistocene hominid-bearing deposits of Latoloi (northern Tanzania). Annals of the Entomological Society of America, v. 93, p. 693-700, 2000.

KERBER, L. \& OLIVEIRA, E.V. Fósseis de vertebrados da Formação Touro Passo (Pleistoceno Superior), Rio Grande do Sul, Brasil: atualização dos dados e novas contribuições. Gaea Journal of Geoscince, v. 4, n. 2, p.49-64, 2008.

KIDWELL, S.M. Condensed deposits in siliciclastic sequences: Expected and observed features. In: EINSELE, G., RICKEN, W., SEILACHER. A. (eds.), Cycles and events in stragraphy. Springer Verlag, Berlin, Pp. 682-695, 1991.

LAUREANO, F.V. O registro sedimentar clástico associado aos sistemas de cavernas Lapa doce e Torrinha, município de
Iraquara, Chapada Diamantina (BA). São Paulo, 1998. Dissertação (Mestrado), Instituto de Geociências, Universidade de São Paulo

LONGRICH, N.R. \& CURRIE, J.P. Albertonykus borealis, a new alvarzsaur (Dinosauria: Theropoda) from the Early Maastrichtian of Alberta, Canada: implications for the systematics and ecology of the Alvarzsauridae. Cretaceous Research, v. 30, p. 239-252, 2009 b.

LYMAN, R.L. (Coord.). Vertebrate Taphonomy. Cambride University Press, Cambridge, 1994.

MAZZA, P.A.; BERTINI, A.; MAGI, M. The Late Pliocene site of Poggio Rosso (Central Italy). Taphonomy and paleoenvirontent: Palaios, v. 19, p. 227-248, 2004.

MOORE, K.L. Anatomia Orientada para a Clínica. Guanabara Koogan, Rio de Janeiro, p. 1146, 1994.

PEREIRA, R.G.F.A. Caracterização geomorfológica e geoespeleológica do carste da bacia do Rio Uma, borda leste da Chapada Diamantina (Município de Itaetê, estado da Bahia). São Paulo, 1998. Dissertação (Mestrado), Instituto de Geociências - Universidade de São Paulo

PORPINO, K.O.; SANTOS, M.F.C.F.; BERGQVIST, L.P. Registro de mamíferos fósseis no Lajedo de Soledade, Apodi, Rio Grande do Norte, Brasil. Revista Brasileira de Paleontologia, v. 7, p. 349-358, 2004.

RIBEIRO, R.C. Assembleia fossilífera do Quaternário tardio de Lagoa do Rumo, Baixa Grande, Bahia. Rio de Janeiro, 2014, p. 150, Tese (Doutorado em Geociências), Universidade Federal do Rio de Janeiro.

RICHARDSON, P.R.K. Carnivore damage on antelope bones and its archaeological implications. Paleontologia Africana, v. 23, p. 109-125, 1980.

SHIPMAN, P. Life History of a Fossil: Introduction to Taphonomy and Paleocology. Havard University Press, Cambridge. p. 222, 1981.

SILVA, H.M. Sistema de informações geográficas do Aquífero Cárstico da micro-região de Irecê, Bahia: Subsídio para a gestão integrada dos recursos hídricos das bacias dos rios Verde e Jacaré. Salvador. 2005. 133 p. Dissertação (Mestrado), Universidade Federal da Bahia

SILVA, J.L.L. Reconstrução paleoambiental baseada no estudo de mamíferos pleistocênicos de Maravilha e Poço das Trincheiras, Alagoas, Nordeste do Brasil. Recife, 2008, 213 p. Tese (Doutorado em Geociências), Universidade Federal de Pernambuco.

SILVA, J.L.L. Tafonomia em mamíferos pleistocênicos: o caso da planície colúvio aluvionar de Maravilha-AL. Recife. 99 p.2001. Dissertação (Mestrado), Universidade Federal de Pernambuco.

TODD, L.C. \& RAPSON, D.J. Long bone fragmentation and interpretation of faunal assemblages: approaches to comparative analysis. Journal of Archaeological Science, v. 15, p. 307-325, 1988 .

TOMASSINI, R.L. \& MONTALVO. C.I. Taphonomic modes on fluvial deposits of the Monte Hermoso Formation (early Pliocene), Buenos Aires province, Argentina. Paleogeography, Paleoclimatology, Peleoecology, v. 369, p. 282-294, 2013.

VILLA, P. \& MAHIEU, E. Breakage patterns of human long bones. Journal of Human Evolution, v. 20, p. 1-22, 1991.

ZUNINO, M.; PAVIA, M.; FERNÁNDEZ-LÓPEZ, S.R.; PAVIA, G. Taphonomic analysis of the Lower Pleistocene Pirro Nord fóssil locality (Pirro 10 site, Puglia, Southern Italy): A depositional model for vertebrate assemblages in a karstic environment. Palaios, v. 27, p. 3-18, 2012.

Submetido em 14 de setembro de 2017 Aceito em 3 de maio de 2019 